\title{
System vicarious calibration of GCOM-C/SGLI visible and near-infrared channels
}

\author{
Hiroshi Murakami ${ }^{1}\left[\right.$ David Antoine ${ }^{2,3} \cdot$ Vincenzo Vellucci $^{3} \cdot$ Robert Frouin $^{4}$
}

Received: 30 June 2021 / Revised: 22 December 2021 / Accepted: 10 January 2022 / Published online: 5 February 2022

(c) The Author(s) 2022

\begin{abstract}
Vicarious calibration coefficients $\left(k_{v}\right)$ of Second-generation GLobal Imager (SGLI) for ocean color processing were derived using in-situ radiometric buoy measurements from the Marine Optical BuoY (MOBY) and the BOUée pour l'acquiSition d'une Série Optique à Long termE (BOUSSOLE). Two aerosol-model look up tables (LUTs) used in the GCOM-C aerosol retrieval algorithm (LUT-A) and in the previous version of ocean color atmospheric correction algorithm (LUT-B) were tested in the procedures to calculate $k_{v}$ and retrieve remote sensing reflectance $\left(R_{\mathrm{rs}}\right)$ and aerosol optical thickness (AOT). Bias of the processed $R_{\mathrm{rs}}$ compared to AERONET-OC $R_{\mathrm{rs}}$ was reduced by applying the determined $k_{v}$ (i.e., corrected SGLI radiance $=$ original SGLI radiance $\left(k_{v}\right.$ ). LUT-A yielded smaller AOT bias compared to AERONET-OC AOT; on the other hand, LUT-B gave smaller $R_{\mathrm{rs}}$ noise due to gentle slope of the aerosol reflectance even though it caused AOT overestimation. When $k_{v}$ was derived by adjusting to the AOT measurements, $k_{v}$ was about 1.1 by LUT-A and 1.2 by LUT-B in the near-infrared (NIR) channel. However, the $k_{v}$ in the NIR channel was close to 1.0 when AOT and land surface reflectance measurements of Radiometric Calibration Network (RadCalNet) were used. The LUT-A with $k_{v}$ from MOBY and BOUSSOLE are currently adopted for the SGLI standard ocean color processing. Improvement is needed, however, to design an optimal LUT suitable for both aerosol and ocean color purposes.
\end{abstract}

Keywords GCOM-C $\cdot$ SHIKISAI $\cdot$ SGLI $\cdot$ Remote sensing $\cdot$ Ocean color $\cdot$ Calibration

\section{Introduction}

Global Change Observation Mission-Climate (GCOM-C), named SHIKISAI, was launched on 23 December 2017 and has been delivering continuous global Earth observations

Hiroshi Murakami

Murakami.hiroshi.eo@jaxa.jp

1 Earth Observation Research Center, Japan Aerospace Exploration Agency, 2-1-1 Sengen, Tsukuba, Ibaraki 305-8505, Japan

2 Remote Sensing and Satellite Research Group, School of Earth and Planetary Sciences, Curtin University, Perth, WA 6845, Australia

3 Sorbonne Université, CNRS Institut de la Mer de Villefranche, IMEV, 06230 Villefranche-sur-Mer, France

4 Scripps Institution of Oceanography, University of California San Diego, 9500 Gilman Drive, La Jolla, CA 92093-0224, USA since 1 January 2018. The GCOM-C satellite carries the Second-generation GLobal Imager (SGLI) and aims to generate a data record for long-term monitoring of environmental change in the global coastal and open ocean. SGLI has multiple channels with high signal-to-noise ratio to detect the small ocean color signal, $250 \mathrm{~m}$ spatial resolution to allow better observation of the coastal oceans, and a wide swath $(1150 \mathrm{~km})$ to observe globally every two to three days (see Table 1).

After the launch, stability of SGLI gains was evaluated (1) by using an internal lamp, (2) by measuring solar light through on-board diffusers (Okamura et al. 2018; Tanaka et al. 2018; Urabe et al. 2020), and (3) by aiming at the moon monthly (Urabe et al. 2019). The temporal change estimated from the lunar irradiance observations is less than $2 \%$ per year and has been considered in the radiometric calibration of the top-of-atmosphere (TOA) radiance, i.e., Level-1B after the Version-2 processing (cf. SHIKISAI portal, https:// shikisai.jaxa.jp/index_en.html). 
Table 1 SGLI observation channels

\begin{tabular}{|c|c|c|c|c|c|c|c|c|}
\hline \multicolumn{2}{|c|}{ Sub-system/channel } & $\begin{array}{l}\text { Center wave- } \\
\text { length } \\
\mathrm{nm}\end{array}$ & $\begin{array}{l}\text { Width } \\
\text { nm }\end{array}$ & Standard radi- & Saturation & $\begin{array}{l}\text { SNR } \\
\text { TI: NE } \Delta T\end{array}$ & $\begin{array}{l}\text { Pixel size } \\
\text { m }\end{array}$ & $\begin{array}{l}\text { Solar irradi- } \\
\text { ance, } \overline{F_{0}} \\
\mathrm{~W} / \mathrm{m}^{2} / \mu \mathrm{m}\end{array}$ \\
\hline \multirow{17}{*}{$\begin{array}{l}\text { VNR (visible } \\
\text { and near- } \\
\text { infrared } \\
\text { radiometer) }\end{array}$} & VN01 & 379.9 & 10.6 & 60 & $240-241$ & $624-675$ & 250/1000 & 1092.1 \\
\hline & VN02 & 412.3 & 10.3 & 75 & $305-318$ & $786-826$ & 250/1000 & 1712.0 \\
\hline & VN03 & 443.3 & 10.1 & 64 & $457-467$ & $487-531$ & 250/1000 & 1898.4 \\
\hline & VN04 & 490.0 & 10.3 & 53 & $147-150$ & $858-870$ & 250/1000 & 1939.2 \\
\hline & VN05 & 529.7 & 19.1 & 41 & $361-364$ & $457-522$ & $\mathbf{2 5 0} / 1000$ & 1851.0 \\
\hline & VN06 & 566.1 & 19.8 & 33 & $95-96$ & $1027-1064$ & 250/1000 & 1797.1 \\
\hline & VN07 & 672.3 & 22.0 & 23 & $69-70$ & 988-1088 & 250/1000 & 1502.6 \\
\hline & VN08 & 672.4 & 21.9 & 25 & $213-217$ & $537-564$ & 250/1000 & 1502.3 \\
\hline & VN09 & 763.1 & 11.4 & 40 & $351-359$ & $1592-1746$ & $250 / 1000$ & 1245.4 \\
\hline & VN10 & 867.1 & 20.9 & 8 & $37-38$ & $470-510$ & 250/1000 & 956.3 \\
\hline & VN11 & 867.4 & 20.8 & 30 & $305-306$ & $471-511$ & 250/1000 & 956.5 \\
\hline & PL01 + 60 & 672.2 & 20.6 & 25 & 295 & 609 & 1000 & 1503.6 \\
\hline & PL01 + 0 & & & & 315 & 707 & & \\
\hline & PL01 - 60 & & & & 293 & 614 & & \\
\hline & PL02 + 60 & 866.3 & 20.3 & 30 & 396 & 646 & 1000 & 956.8 \\
\hline & PL02 + 0 & & & & 424 & 763 & & \\
\hline & PL02 - 60 & & & & 400 & 752 & & \\
\hline \multirow{6}{*}{$\begin{array}{l}\text { IRS (infrared } \\
\text { scanner) }\end{array}$} & SW01 & 1050 & 21.1 & 57 & 289.2 & 951.8 & 1000 & 646.5 \\
\hline & SW02 & 1390 & 20.1 & 8 & 118.9 & 347.3 & 1000 & 361.2 \\
\hline & SW03 & 1630 & 195.0 & 3 & 50.6 & 100.5 & 250/1000 & 237.6 \\
\hline & SW04 & 2210 & 50.4 & 1.9 & 21.7 & 378.7 & 1000 & 84.2 \\
\hline & TI01 & 10,785 & 756 & $300 \mathrm{~K}$ & $340 \mathrm{~K}$ & $0.08 \mathrm{~K}$ & $\mathbf{2 5 0} / 500 / 1000$ & - \\
\hline & TI02 & 11,975 & 759 & $300 \mathrm{~K}$ & $340 \mathrm{~K}$ & $0.13 \mathrm{~K}$ & $\mathbf{2 5 0} / 500 / 1000$ & - \\
\hline
\end{tabular}

SNR is defined as input radiance/noise at the level of standard radiance and IFOV shown by bold characters. After Okamura et al. (2018) with solar irradiance of Thuillier et al. (2003)

In addition to the onboard calibration, vicarious calibration is required for atmospheric correction of SGLI imagery because radiometric calibration, especially inter-band calibration, should be accurate to about $0.1 \%$ for ocean color applications (Gordon 1998; Franz et al. 2007; Zibordi et al. 2015). The vicarious calibration determines a set of correction factors (or "vicarious calibration gains") to adjust the satellite TOA radiance so that derived above surface water-leaving reflectance $\rho_{\mathrm{w}}$ (or remote sensing reflectance, $R_{\mathrm{rs}}$ ) values are consistent with in-situ observed quantities through the atmospheric radiative transfer calculation (Eplee et al. 2001; Yoshida et al. 2005; Franz et al. 2007; Zibordi and Melin 2017).

The traditional ocean color atmospheric correction (AC) estimates the aerosol optical thickness (AOT) and aerosol model $\left(M_{\text {aerosol }}\right)$ by using the satellite TOA radiance in two near-infrared (NIR) bands where the $\rho_{\mathrm{w}}$ is negligible over clear Case 1 waters. In the case of SGLI AC, the NIR band at $867 \mathrm{~nm}(\mathrm{VN} 10)$ and the red band at $672 \mathrm{~nm}$ (VN07) must be used instead of the second NIR band at $763 \mathrm{~nm}$ which is designed for observation of the $\mathrm{O}_{2}$ gaseous absorption and is not suitable for the AC. So, $\rho_{\mathrm{w}}$ at $672 \mathrm{~nm}$ must be preassumed from its value in other visible wavelengths through iterative calculations (e.g., Gordon and Wang 1994; Wang and Gordon 1994; Antoine and Morel 1999; Siegel et al. 2000; Toratani et al. 2007). The $\rho_{\mathrm{w}}$ in visible bands is then obtained by correcting the TOA radiance for atmospheric scattering and transmittance, which are calculated from the estimated aerosol properties represented by AOT and $M_{\text {aerosol }}$. In the case of vicarious calibration, however, we can use in-situ observed $\rho_{\mathrm{w}}$ in the two AC bands to estimate AOT and $M_{\text {aerosol }}$.

For the in-situ reference data set, we used data from the Marine Optical BuoY (MOBY) and the BOUée pour l'acquiSition d'une Série Optique à Long termE (BOUSSOLE) which are widely used for the vicarious calibration of global ocean color sensors (Clark et al. 1997; Eplee et al. 2001; Antoine et al. 2008a). The consistency calibration reference among satellite ocean color sensors can be improved by commonly referencing to the MOBY and BOUSSOLE measurements (Zibordi et al. 2016). 
In this paper, we derive vicarious calibration coefficients $k_{v}$ for ocean color processing by using $\rho_{\mathrm{w}}$ from MOBY and BOUSSOLE and two aerosol lookup tables (LUTs) which are used in the GCOM-C standard aerosol property algorithm (Yoshida 2020; Yoshida et al. 2021) and the ocean color AC algorithm (Toratani et al. 2020; 2021). The $R_{\mathrm{rs}}$ derived by applying the $k_{v}$ and using the same LUTs is validated against $R_{\mathrm{rs}}$ observed by Aerosol Robotic NetworkOcean Color (AERONET-OC) (Zibordi et al. 2006, 2009, 2021). The matchup dataset includes a large range of ocean color, surface reflectance, and aerosol conditions. The estimation error and sensitivity of $R_{\mathrm{rs}}$ and AOT on the $k_{v}$ are evaluated for the two sets of aerosol LUTs. The pre-fixed $k_{v}$ in the red and NIR channels are discussed by referring them to those obtained from the aerosol and surface reflectance observations of AERONET-OC and those of the Radiometric Calibration Network (RadCalNet) (Bouvet et al. 2019).

\section{Data}

\subsection{GCOM-C SGLI Level-1B data}

Both Versions 1 and 2 Level-1B (L1B) data were used, the former for 2018 and 2019, and the latter for observations from January 2020, because the Version 2 reprocessing was underway at the time of May 2021. Version 2 L1B includes a correction of temporal degradation of the radiometric gains by the monthly moon calibration and a deselection of noisy detectors in the unilluminated edge parts of the detector arrays which are used for estimating the dark current of the sensor outputs. We have converted Version $1 \mathrm{~L} 1 \mathrm{~B}\left(L_{\mathrm{V} 2}\right)$ to Version 2-like L1B $\left(L_{\mathrm{V} 1}\right)$ approximately by correcting the temporal change of gain $\left(k_{\mathrm{t}}\right)$ and offset $\left(k_{\mathrm{o}}\right)$ before the vicarious calibration analysis using days from launch $(D)$ as follows:

$L_{V 2}(\lambda) \sim\left(L_{V 1}(\lambda)-k_{o}(D)\right) /\left(1.0+k_{t}(\lambda) \cdot D\right)$

$k_{o}(D)=a_{0}(\lambda)+a_{1}(\lambda) \cdot D+a_{2}(\lambda) \cdot D^{2}$

The coefficients, $k_{t}$ and $a_{i}(i=0,1$, and 2), are shown in the homepage: https://suzaku.eorc.jaxa.jp/GCOM_C/data/ prelaunch/index_cal.html). The correction is not needed for Version 2 L1B data which was processed after 29 June 2020.

\subsection{MOBY data}

MOBY has been operated off the Lanai Island in Hawaii (around $20.82^{\circ} \mathrm{N}, 157.19^{\circ} \mathrm{W}$ in the 271 st deployment) since July 1997 (Clark et al. 1997, 2003), and currently a National Oceanic and Atmospheric Administration (NOAA) funded project to provide vicarious calibration of ocean color satellites (https://coastwatch.noaa.gov/cw/field-observatio ns/MOBY.html). The normalized water-leaving radiance calculated from the MOBY spectral observations by SGLI relative response function (Uchikata et al. 2014) and available from the NOAA CoastWatch homepage (see above) was used in this study.

\subsection{BOUSSOLE data}

BOUSSOLE has been operated in the Western Mediterranean Sea, $60 \mathrm{~km}$ off Nice, $\left(43.37^{\circ} \mathrm{N}, 7.90^{\circ}\right.$ E) since September 2003 (Antoine et al. 2006, 2008a; b). The $R_{\mathrm{rs}}$ used in this study was derived from hyperspectral measurements weighted by SGLI spectral response functions. The averages of $R_{\mathrm{rs}}$ in the BOUSSOLE blue channels (average $R_{\mathrm{rs}}$ of 0.0042 at $443 \mathrm{~nm}$ ) are about two times smaller than those in the MOBY blue channels (average $R_{\mathrm{rs}}$ of 0.0087 at $443 \mathrm{~nm}$ ). This difference is due to BOUSSOLE data encompassing oligotrophic and mesotrophic conditions while conditions at MOBY are always oligotrophic. Another reason is that, for a given chlorophyll concentration, Case I waters of the Mediterranean Sea exhibit a larger contribution of absorption by colored dissolved organic matter than other oceans (Morel and Gentili 2009; Morel et al. 2007).

\subsection{AERONET-OC data}

AERONET-OC (Zibordi et al. 2006, 2009, 2021) provides above-water radiometric data gathered with a system initially developed for atmospheric measurements of direct sun-irradiance and sky-radiance measurements and completed with a sea-viewing capability to derive reflectance. The uncertainty is at the 4-5\% level for the water-leaving radiance data in the blue-green spectral regions (Zibordi et al. 2009). We used the data from 23 AERONET-OC sites which operated in 2018-2020 to evaluate the influence of the vicarious calibration coefficients on $R_{\mathrm{rs}}$ (see Sect. 4.2). The multi-band data were converted to $\rho_{\mathrm{w}}$ in the SGLI visible-NIR channels through the in-water model described in Appendix.

\subsection{RadCalNET data}

RadCalNet (Bouvet et al. 2019) is an initiative of the Working Group on Calibration and Validation (WGCV) of the Committee on Earth Observation Satellites (CEOS) and provides a continuously updated archive of surface and TOA reflectances over a network of sites (currently, University of Arizona's site at Railroad Playa, Nevada, USA, the ESA/CNES site in Gobabeb, Namibia, AIR's site at Baotou, China, the CNES site at La Crau, France, the new AIR sandy site at Baotou, China) (https://www.radcalnet.org/). We used the Railroad Playa and Gobabeb sites which are 
relatively homogeneous at the scale of several kilometers. We calculated land surface reflectance of SGLI channels from the RadCalNet measurements (at a $10 \mathrm{~nm}$ spectral sampling interval, in the spectral range from 380 to $2500 \mathrm{~nm}$ and at 30 min intervals) of the nearest time by weighting the spectral response functions of the SGLI channels. The datasets include atmospheric observations including surface atmospheric pressure, column-integrated water vapor and ozone, AOT at $550 \mathrm{~nm}$, and aerosol Ångström exponent.

\subsection{JMA objective analysis data}

Column-integrated ozone and water vapor, sea surface wind speed, and surface pressure data were provided by the Japan Meteorological Agency (JMA). The ozone data are produced by the Meteorological Research Institute global chemistryclimate model (MRI-CCM2) (Deushi and Shibata 2011) which includes both the physical processes such as transport, vertical diffusion and deposition, and chemical processes between trace gases (Shibata et al. 2005). These ancillary data were interpolated to the observation times and locations of the match-up data.

\section{Methods}

\subsection{Data processing flow of vicarious gain calculation}

Figure 1 gives a schematic description of the vicarious calibration procedure. It involves computing the TOA reflectance, $\rho_{\mathrm{t}}$, in the near-ultraviolet (NUV) and visible bands from in situ $\rho_{\mathrm{w}}$ measurements and aerosol properties determined at NIR wavelengths and comparing the simulated reflectance with the SGLI reflectance.

The satellite observed TOA reflectance, $\rho_{\mathrm{t}}$, can be approximated as follows: $\rho_{\mathrm{t}} / t_{\mathrm{g}}=\rho_{\mathrm{r}}+\rho_{\mathrm{a}}+t \rho_{\mathrm{w}} /\left(1-s_{\mathrm{a}} \rho_{\mathrm{w}}\right)+T \rho_{\mathrm{g}}$

All the terms in Eq. (3) are function of the wavelength ( $\lambda$ ) but not shown in the equations here. The $\rho_{\mathrm{t}}$, can be calculated from the satellite observed radiance, $L_{\mathrm{TOA}}$, by using the ratio of sun-earth distance to mean sun-earth distance, $\mathrm{d}$, the SGLI band weighted extraterrestrial solar irradiance, $F_{0}\left(F_{0}\right.$ at the yearly average $\mathrm{d}, \overline{F_{0}}$, is shown in Table 1$)$, and solar zenith angle $\theta_{\mathrm{s}}$ as follows:

$\rho_{\mathrm{t}}=L_{\mathrm{TOA}} \pi /\left(F_{0} \cos \left(\theta_{\mathrm{s}}\right)\right)$

$F_{0}=\overline{F_{0}} / d^{2}$

Atmospheric molecular scattering reflectance, $\rho_{\mathrm{r}}$ (calculated as the satellite reflectance for AOT $=0$ and $\rho_{\mathrm{w}}=0$ ), aerosol reflectance, $\rho_{\mathrm{a}}$, sunglint reflectance, $\rho_{\mathrm{g}}$, direct + diffuse transmittance of sun-surface-satellite path, $t$, correction ratio of gaseous $\left(\mathrm{O}_{3}, \mathrm{O}_{2}\right.$, and $\left.\mathrm{H}_{2} \mathrm{O}\right)$ absorption from the US standard atmosphere, $t_{\mathrm{g}}$, direct transmittance of sun-surface-satellite path, $T$, and spherical albedo, $s_{\mathrm{a}}$, are calculated using the Pstar4 radiative transfer code for AOT at $867 \mathrm{~nm}$ (VN10), nine or ten aerosol models, $M_{\text {aerosol }}$, and observation geometries (satellite zenith, satellite azimuth, solar zenith, and solar azimuth angles), and stored in look up tables (LUTs). The Pstar4 is a vector radiative transfer model for a coupled atmosphere-ocean system (Nakajima and Tanaka 1986; 1988; Ota et al. 2010), and the scheme is based on the discrete ordinate methods (Stamnes et al. 1988). The atmospheric gas transmittance is modeled as a function of column-integrated ozone and water vapor (WV), and oxygen (represented by sea-level pressure, SLP). The surface reflectance condition in the Pstar4 was set by a Lambertian surface for the RadCalNet, and a flat ocean surface for other calculations.

The in-situ $\rho_{\mathrm{w}}$ are converted from the measured reflectance at geometries of in-situ sensor and solar angles to ones at geometries of satellite sensor and solar angles through
Fig. 1 Flow chart of SGLI vicarious calibration

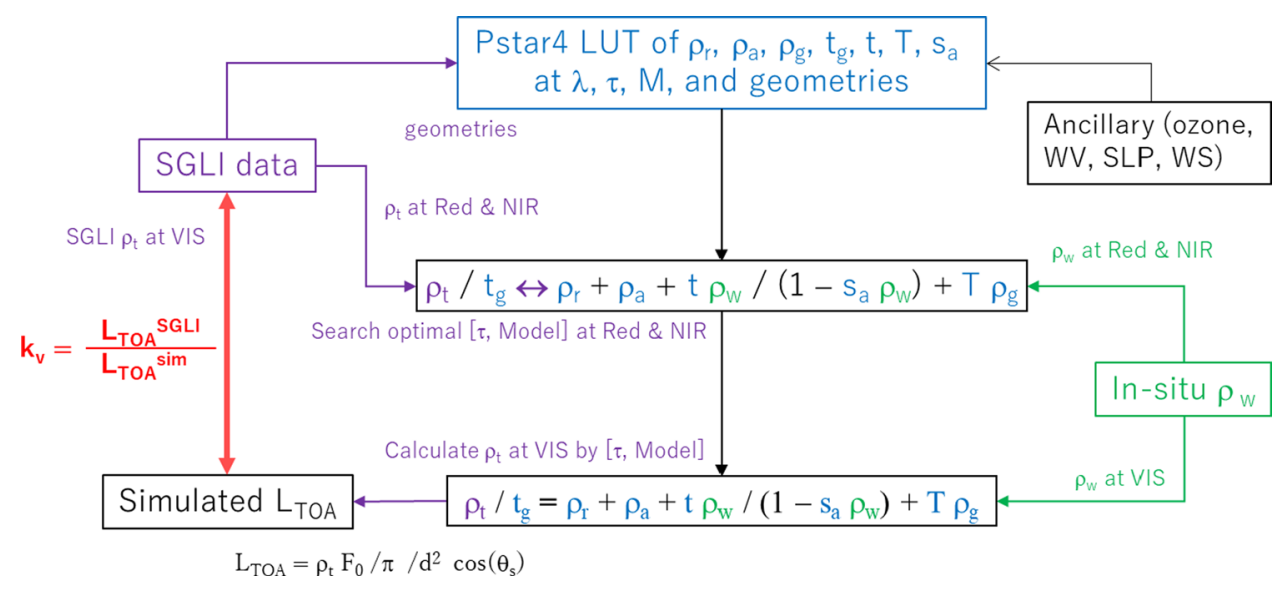


the bidirectional reflectance distribution function (BRDF) proposed by Morel et al. (2002). If NIR is not observed by in-situ instruments, $\rho_{\mathrm{w}}$ at NIR is estimated by Inherent Optical Property (IOP) model applying observation/simulation ratio at the neighboring red channel $\rho_{\mathrm{w}}$ (see Appendix).

$\rho_{\mathrm{t}}$ is simulated by using in-situ $\rho_{\mathrm{w}}, \rho_{\mathrm{g}}$, and the LUT variables $\left(t_{\mathrm{g}}, \rho_{\mathrm{r}}, \rho_{\mathrm{a}}, s_{\mathrm{a}}, t, T\right)$ at selected AOT at V10 $(867 \mathrm{~nm})$ and model number $M_{\text {aerosol }}$. The glint reflectance $\rho_{\mathrm{g}}$ is estimated by Cox and Munk (1954) using objective analysis of sea surface wind speed data, but it did not significantly affect to $k_{v}$ in this study because we used observations with $\rho_{\mathrm{g}}<0.004$ (the influence of the $\rho_{\mathrm{g}}$ on $k_{v}$ was less than 0.001 except for the $\mathrm{O}_{2}$ absorption channel VN09). The estimation of the AOT and model number $M_{\text {aerosol }}$ are described in Sect. 3.2.

We defined the $k_{v}$ in each spectral band as SGLI observed radiance $L_{\mathrm{TOA}}$ SGLI divided by simulated radiance $L_{\mathrm{TOA}}{ }^{\text {sim }}$ estimated from the reference as follows:

$k_{v}=L_{\mathrm{TOA}}{ }^{\mathrm{SGLI}} / L_{\mathrm{TOA}}{ }^{\text {sim }}$

So, the corrected radiance can be obtained by dividing $L_{\mathrm{TOA}}{ }^{\text {SGLI }}$ by $k_{v}$. Practically $k_{v}$ is derived by linear regression of $L_{\mathrm{TOA}}{ }^{\text {sim }}$ and $L_{\mathrm{TOA}}{ }^{\text {SGLI }}$ with passing the origin, i.e.

$k_{v}=\sum_{i=1}^{N}\left(L_{\mathrm{TOA}} \mathrm{SGLI}_{i} \cdot L_{\mathrm{TOA}}{ }^{\operatorname{sim}_{i}}\right) / \sum_{i=1}^{N}\left(L_{\mathrm{TOA}}{ }^{\mathrm{sim}_{i}}\right)^{2}$,

where $N$ is the number of samples. The deviation of each sample from the $k_{v}$ is defined as follows:

$\mathrm{SD} k_{v}=\sqrt{\sum_{i=1}^{N}\left(\frac{L_{\mathrm{TOA}}{ }^{\mathrm{SGLI}_{i}}}{L_{\mathrm{TOA}}{ }^{\operatorname{sim}_{i}}}-k_{v}\right)^{2} / N}$.

The $95 \%$ confidence level is estimated from $\mathrm{SD} k_{v}$ multiplied by the critical values of Student's $t$ distribution.

\subsection{Estimation of AOT and $M_{\text {aerosol }}$}

\subsubsection{SGLI NIR and red channels}

AOT and $M_{\text {aerosol }}$ are searched in the LUT by matching $\rho_{\mathrm{t}}$ calculated with Eq. (3) and in-situ $\rho_{\mathrm{w}}$ with SGLI observed $\rho_{\mathrm{t}}$ in the NIR and red channels (VN10 and VN07). Therefore, $k_{v}$ for both NIR and red bands is fixed to 1.0.

\subsubsection{In-situ AOTs}

AOT at $443 \mathrm{~nm}$ (VN03) is estimated from AERONET-OC AOT at NIR and the LUT for each $M_{\text {aerosol }}$. Optimal $M_{\text {aerosol }}$ is searched by comparing the AOT estimated by LUT and the in-situ AOT at $443 \mathrm{~nm}$. In the case of RadCalNet, the process is the same as AERONET-OC except that AOT at
$443 \mathrm{~nm}$ and $672 \mathrm{~nm}$ is calculated from in-situ measurements of AOT at $500 \mathrm{~nm}$ and Ångström exponent, $\alpha$, using Eq. (9).

$\operatorname{AOT}\left(\lambda_{2}\right) / \operatorname{AOT}\left(\lambda_{1}\right)=\left(\lambda_{2} / \lambda_{1}\right)^{-\alpha}$

We used $\lambda_{1}=500 \mathrm{~nm}$ and $\lambda_{2}=443 \mathrm{~nm}(\mathrm{VN} 03)$ or $\lambda_{2}=672 \mathrm{~nm}$ (VN08) in this study. In this case, $k_{v}$ are adjusted to fit to the AERONET-OC AOT in the two channels. Using the derived $k_{v}$ in the red (VN07) and NIR (VN10) channels, $k_{v}$ in the other channels are derived by the same way as Sect. 3.1 using the MOBY + BOUSSOLE data.

\subsection{Aerosol LUTs}

We use two LUTs with different aerosol model sets to evaluate vicarious calibration coefficients. The first aerosol LUT (LUT-A) was built as in Yoshida et al. (2018), i.e., including fine and coarse aerosols with mode radii of $0.143 \mu \mathrm{m}$ and $2.59 \mu \mathrm{m}$ (deviation of 1.537 and 2.054, respectively) for lognormal distribution, with, however, negligible absorption (imaginary part of the refractive indexes are set to very small values, $1.010^{-8}$ and $3.010^{-9}$ ) in the Pstar4 code. The fine aerosol model is based on the average properties of the fine mode (category 1-6 by Omar et al. 2005) derived from AERONET measurements, and the coarse aerosol model is the pure marine aerosol by Sayer et al. (2012). The hygroscopic growth effect (affecting the mode radius and refractive index) was not included here. This aerosol model is also used for the LUT of the SGLI land atmospheric correction (Murakami 2020) and the version 3 ocean atmospheric correction (Toratani et al. 2021). The SGLI standard aerosol algorithm is based on the aerosol size distribution of LUT-A, but it estimates the aerosol absorption by mixing absorptive particles with refractive indices of the soot and the dust particles for the fine and coarse aerosols, respectively (Yoshida et al. 2018).

The second aerosol LUT (LUT-B) was calculated as per Shettle and Fenn (1979) which includes the hygroscopic growth of the aerosol particles, by which the mode radius of the fine and coarse aerosols increases from $0.192 \mu \mathrm{m}$ to $0.331 \mu \mathrm{m}$ and from $2.13 \mu \mathrm{m}$ to $6.31 \mu \mathrm{m}$, respectively. This aerosol model is used for the LUT in the SGLI version 2 ocean atmospheric correction algorithm (Toratani et al. 2020).

Figure 2 displays the aerosol reflectance as a function of wavelength for the two LUTs. LUT-A has a wider range of spectral slope of aerosol reflectance. The large difference of the aerosol spectral slopes between LUT-A and LUT-B is caused by the size distribution (especially the mode radius of small particle is smaller in LUT-A than that in LUT-B) and aerosol light absorption is not considered in LUT-A. 
Fig. 2 Aerosol models for vicarious calibration LUTs. The upper (A) and the lower (B) panels show aerosol reflectance as a function of wavelength for LUT-A and LUT-B, respectively
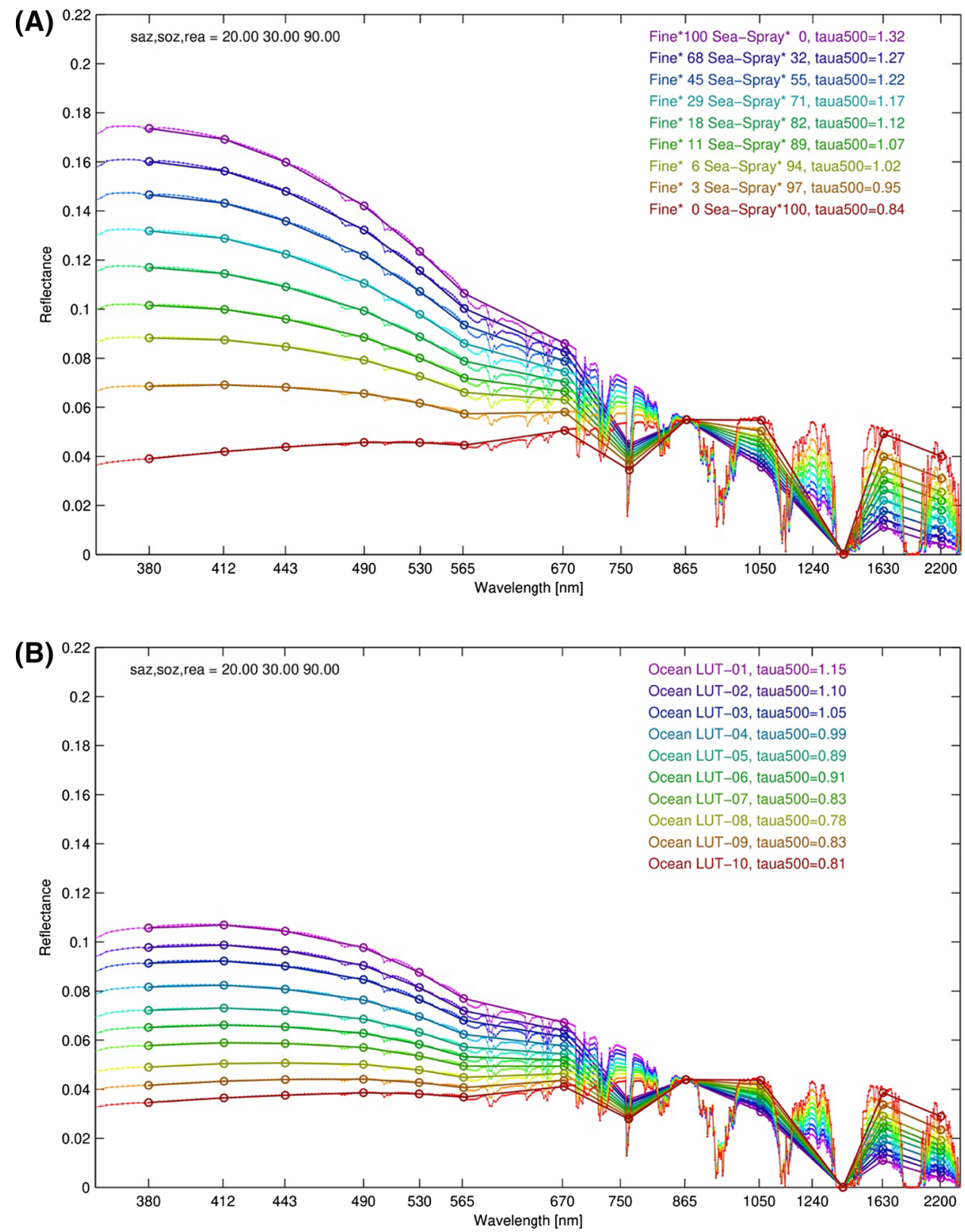

\subsection{Quality control of input data}

SGLI $3 \times 3$-pixel average data centered on the in-situ sites with observation time difference of less than $\pm 2 \mathrm{~h}$ were used in the analysis but excluding the following conditions, (i)-(vii). The number of excluded samples, $N$, with respect to total number of samples acquired over MOBY + BOUSSOLE is shown as (N/input total number, where the denominator is 189).

(i) The average of $3 \times 3$ NIR reflectance is larger than 0.1 (to avoid cloudy pixels, 19/189), (ii) The standard deviation of $3 \times 3$ NIR reflectance is larger than 0.001 (to avoid small cloud contamination, 48/189),

(iii) AOT in the NIR channel is less than 0 or larger than 0.15 (for LUT-A) or 0.185 (for LUT-B; same samples were selected when it was 0.185 because the LUT-B causes larger AOT than LUT-A) (to exclude cases of shadow or dense aerosol, 55/189),

(iv) $\alpha$ is less than -0.5 or larger than 2.5 when AOT $>0.05$ (irregular aerosol model selection by irregular spectral slope in the observation, 13/189),

(v) $\rho_{\mathrm{g}}$ is larger than 0.004 (to avoid sun glint areas, 78/189), 
(vi) Difference between reflectance of VN10 and one of VN11 is larger than 0.004 (to avoid sunglint areas (VN10 and VN11 have the same wavelength, but there is parallax, and the presence of sunglint causes a difference in reflectance), 59/189),

(vii) Difference between observed and simulated reflectance of VN09 is larger than 0.008 (to avoid cloud contamination which can reduce the path length and absorption in the $\mathrm{O}_{2} \mathrm{~A}$ band, 48/189).

Solar zenith angles less than $70^{\circ}$ were used in this analysis. We did not limit data selection by maximum satellite zenith angle $\theta_{\mathrm{v}}$ because $\theta_{\mathrm{v}}$ of SGLI visible and near-infrared non-polarized (VNR-NP) channels is less than about $40^{\circ}$. In the case of RadCalNet, we excluded the data of $\theta_{\mathrm{v}}$ larger than $10^{\circ}$ to avoid the influence of the land surface BRDF which is not corrected for in this study, and water vapor content was limited to $30 \mathrm{~kg} / \mathrm{m}^{2}$ to minimize the influence of water vapor absorption and possibly cloudy conditions.

\subsection{Influence of the vicarious calibration coefficients on $R_{\text {rs }}$ and AOT}

The $R_{\mathrm{rs}}$ and AOT were calculated with the same processing scheme except for inputting SGLI $\rho_{\mathrm{t}}$ and outputting $\rho_{\mathrm{w}}$ in the blue-green channels in Eq. (3). In-situ $\rho_{\mathrm{w}}$ at NIR and red wavelengths are used for the estimation of $\rho_{\mathrm{w}}$ at visible wavelengths to see just the effect of $k_{v}$. The $R_{\mathrm{rs}}$ and AOT are evaluated by comparing the matchups of AERONET-OC for LUT-A and LUT-B. The quality control is the same as in Sect. 3.4 except that the maximum AOT is 0.6 instead of 0.15 . Sensitivity of $R_{\mathrm{rs}}$ and AOT to $k_{v}$ was investigated for the two aerosol tables, LUT-A and LUT-B, by adding or subtracting $1 \%$ to $\rho_{\mathrm{t}}$ of the match-up observations.
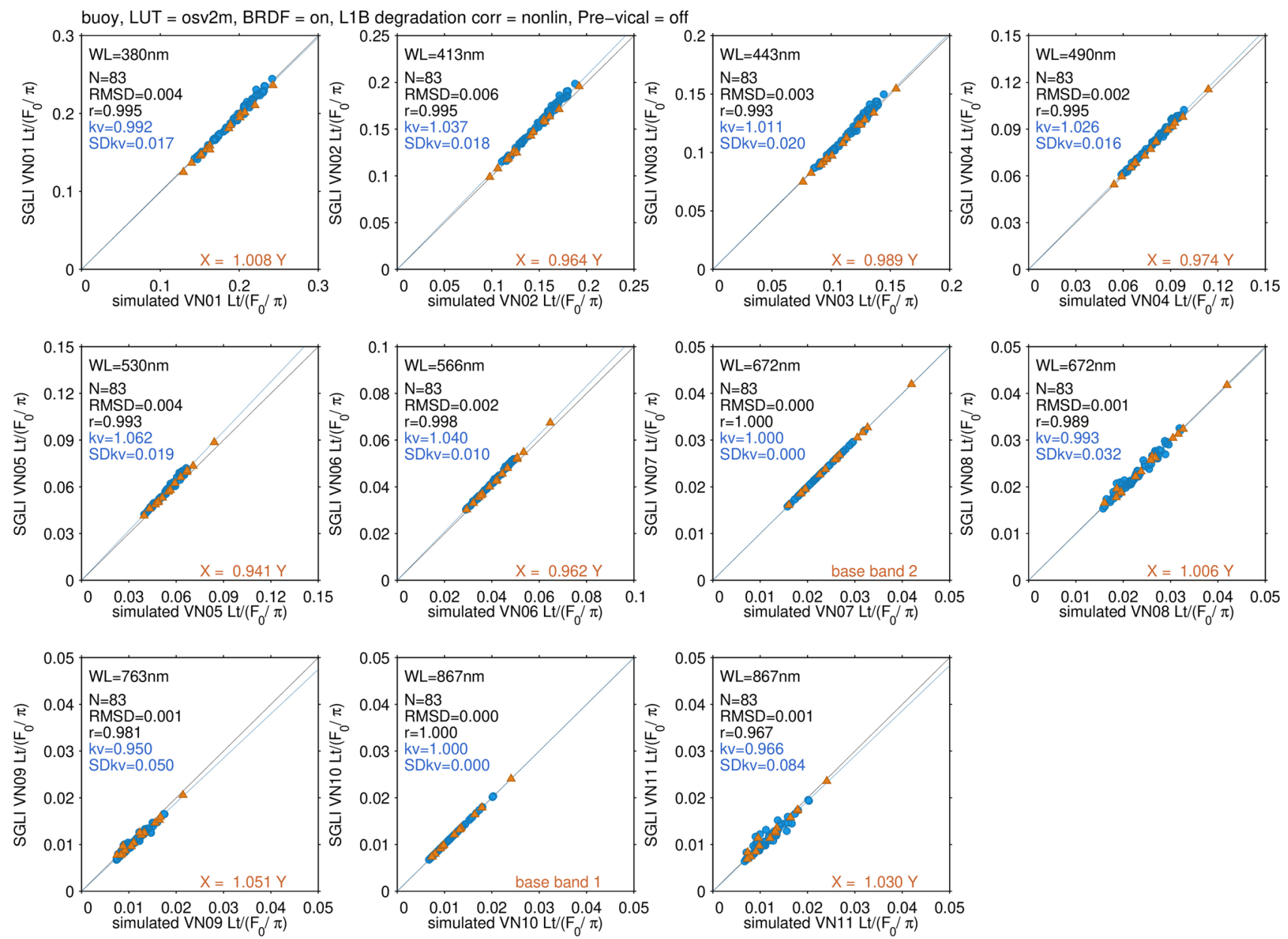

Fig. 3 Scatter diagram of SGLI and simulated radiance normalized by $F_{0} / \pi\left(L_{\mathrm{TOA}} /\left(F_{0} / \pi\right)\right)$ calculated at MOBY (69 blue dots) and BOUSSOLE (14 red triangles). LUT-A was used to derive the simulated reflectance. $\mathrm{N}$ indicates sample number, RMSD, root mean square

difference, $\mathrm{r}$, correlation coefficient, and $\mathrm{SD} k_{v}$ are explained in the text. The blue line shows the line of $Y=k_{v} X$. The regression by the inverse equation ( $X=a Y, a$ is the slope) is show in each panel 
Fig. 4 Summary plots of $k_{v}$ of SGLI derived by using a MOBY, b BOUSSOLE, and c MOBY + BOUSSOLE by using LUT-A ((a)-(c), solid lines) and LUT-B ([a]-[c], dashed lines). The $95 \%$ confidence level (assuming the $t$-distribution) is shown by the error bars. The horizontal positions are shifted to avoid the overlap of the plots

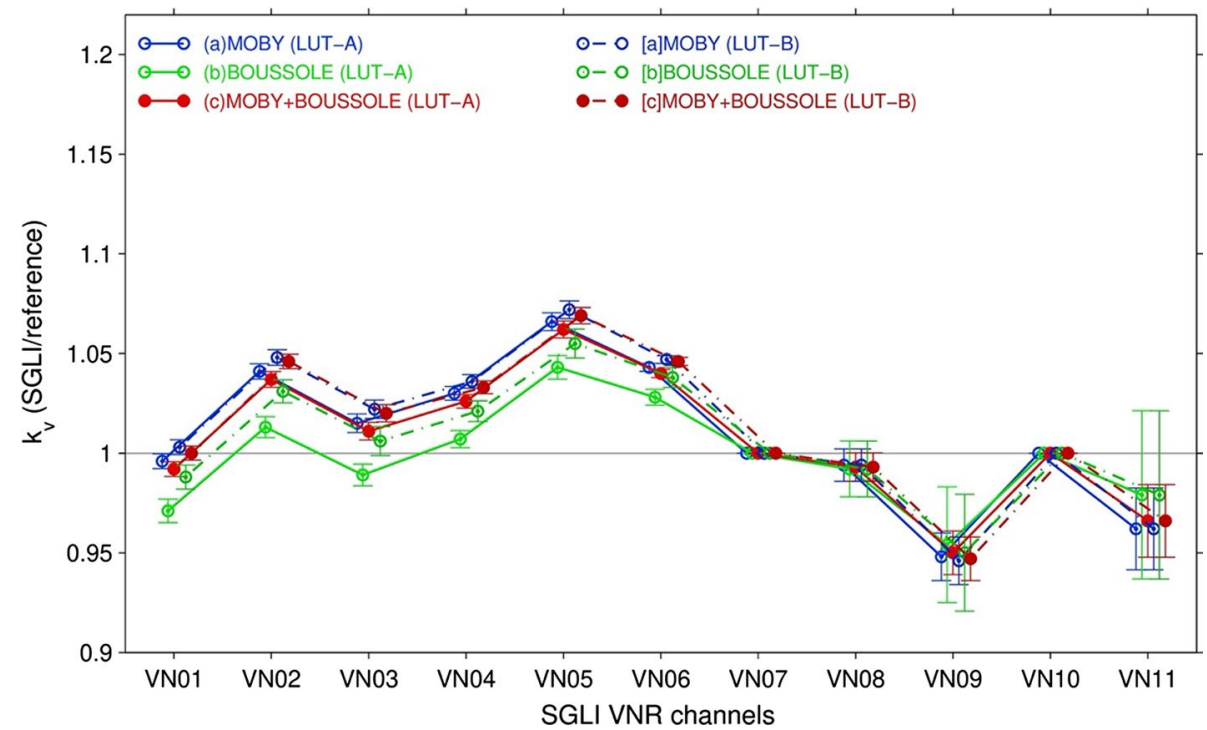

\subsection{Evaluation of $\boldsymbol{R}_{\mathrm{rs}}$ and AOT estimates before and after applying $\boldsymbol{k}_{v}$}

\subsection{MOBY and BOUSSOLE}

Figure 3 shows the comparison between simulated and SGLI observed $L_{\mathrm{TOA}}$ after normalizing by $F_{0} / \pi$ when using the LUT-A. The derived $k_{v}$ for either MOBY or BOUSSOLE or both together with the LUT-A and LUT-B are shown in Fig. 4 and listed in Table 2. The SD $k_{v}$ and the 95\% confidence levels calculated from $\mathrm{SD} k_{v}$ are displayed in Table 3 and by vertical bars in Fig. 4. Note that the BRDF correction affected $k_{v}$ by about 0.004 and reduced the $\mathrm{SD} k_{v}$ by about 0.002 at $443 \mathrm{~nm}$ (VN03).

The six sets of $k_{v}$ have a similar spectral shape as follows: higher than 1.0 at VN02, VN04, VN05, and VN06 channels ( $k_{v}$ larger than 1.0 indicates that the SGLI radiance is larger than radiance expected from MOBY + BOUSSOLE data and the LUTs) and around 1.0 in VN01 and VN03 channels; on the other hand, $k_{v} \mathrm{~s}$ in VN08, VN09 and VN11 are smaller than 1.0. The 95\% confidence levels are larger than the differences among $k_{v}$ s of (a)-(c), [a]-[c] at the red-NIR wavelengths due to relatively large influence from the errors of the aerosol reflectance estimation.

The $k_{v}$ s by MOBY are larger than ones by BOUSSOLE in VN01-06: the difference between $k_{v}$ at $443 \mathrm{~nm}$ (VN03) from MOBY and BOUSSOLE is $2.6 \%$ in the case of LUT-A and $1.6 \%$ in the case of LUT-B (Fig. 4 and Table 2). The $k_{v}$ s by LUT-B ([a]-[c]) are larger than ones by LUT-A ((a)-(c)) by about $0.7 \%$ (MOBY) and 1.7\% (BOUSSOLE) at $443 \mathrm{~nm}$. The $k_{v}$ s by MOBY + BOUSSOLE is closer to ones by MOBY because the sample number for MOBY is five times larger than the sample number for BOUSSOLE.
SGLI derived $R_{\mathrm{rs}}$ and AOT were evaluated against the AERONET-OC matchups by using the two sets of $k_{v}((\mathrm{c})$ and [c] of Table 2) that were derived with the two LUTs. The matchup sites are distributed various geographical areas near the coast (Fig. 5). The results by LUT-A are displayed in Fig. 6 and both results are listed in Table 4. In-situ $\rho_{\mathrm{w}}$ in VN07 and VN10 were used to estimate the aerosol properties for the AC because we intend to see the effect of $k_{v}$ simply without influence of the estimation errors of the non-zero water leaving reflectance in the $\mathrm{AC}$ algorithms.

The bias in Table 4 is improved after applying $k_{v}$ in VN01, VN05, and VN06 in the case of LUT-A, and in VN02, VN04, VN05, and VN06 in the case of LUT-B. RMSD of $R_{\mathrm{rs}}$ in VN01-VN04 channels by LUT-A is larger than one by LUT-B. On the other hand, the positive bias of AOT by LUT-B is larger than one by LUT-A.

\subsection{Sensitivity of $\boldsymbol{R}_{\mathrm{rs}}$ and AOT to $\boldsymbol{k}_{v}$ deviation}

Figure 7 shows the sensitivity of $R_{\mathrm{rs}}$ and AOT to $k_{v}$ deviation. When $\pm 1 \%$ error is added to $k_{v}$ of each visible channel, the influence on $R_{\mathrm{rs}}$ in the same channel is about $\pm 1 \%$ multiplied by the transmittance along the light path, $t$ (ranged from 0.6 to 0.8 in violet-green wavelengths), for both aerosol models according to Eq. (3).

When $\pm 1 \%$ error is added to $k_{v}$ of NIR channel (VN10), $R_{\mathrm{rs}}$ in visible channels is impacted by the same sign. On the other hand, $\pm 1 \%$ error on $k_{v}$ of red channel (VN07) causes the opposite sign error on $R_{\mathrm{rs}}$ in visible channels. This indicates that the $R_{\mathrm{rs}}$ errors are suppressed when errors at NIR and red channels have the same sign but enhanced when the errors have the opposite sign. It is notable that errors of $R_{\mathrm{rs}}$ 

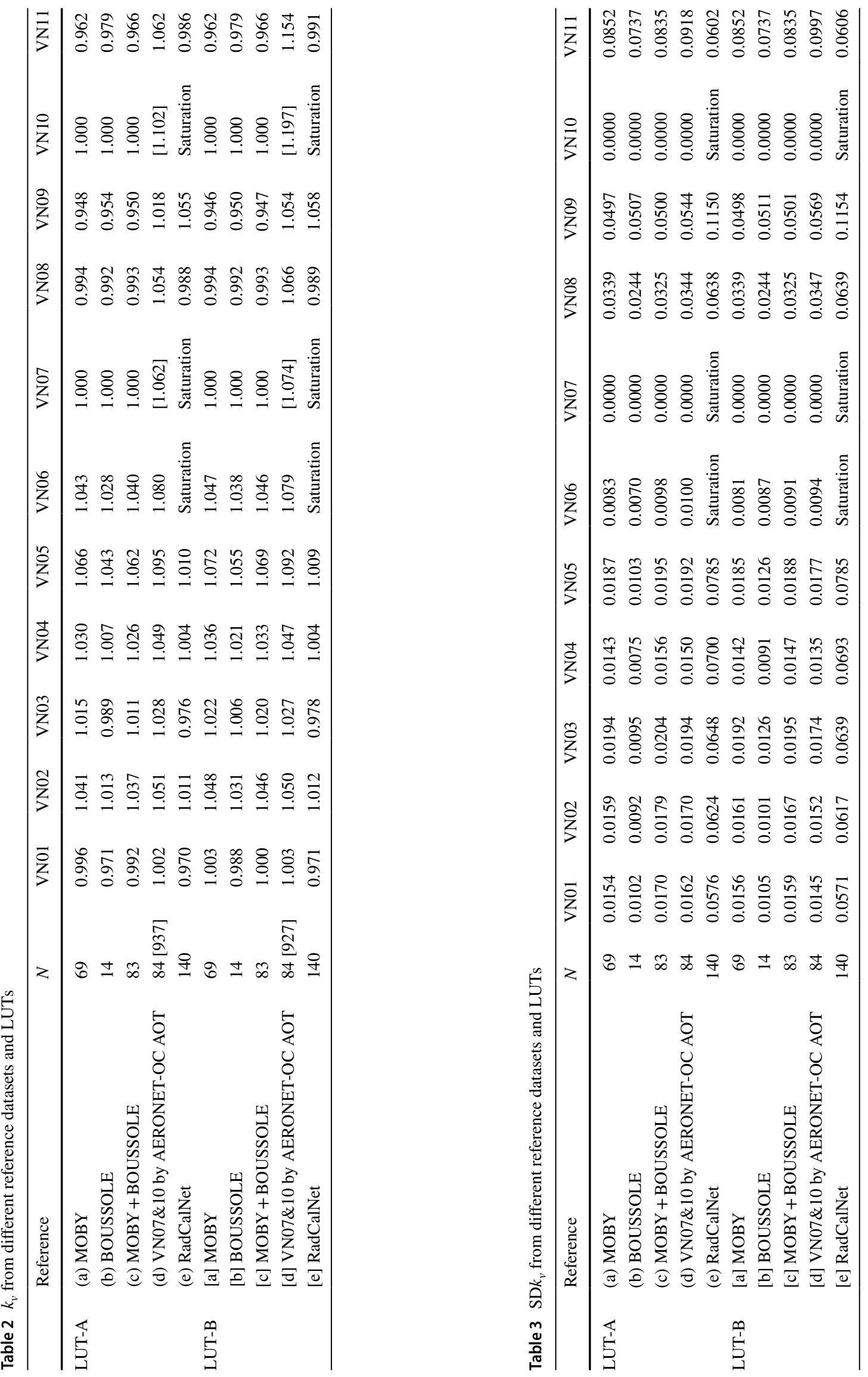


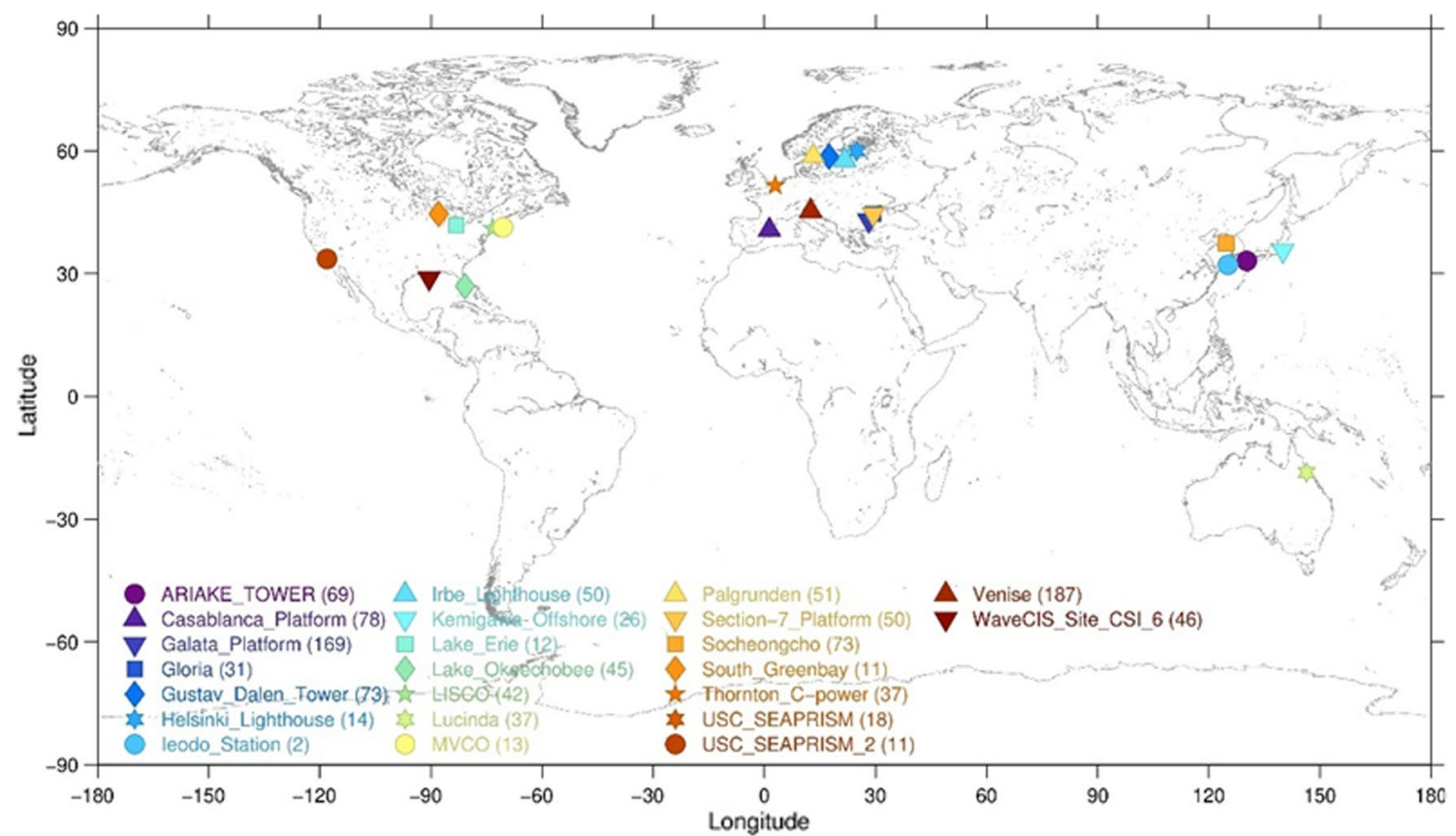

Fig. 5 Distribution of AERONET-OC sites. The marker colors correspond to the ones in Fig. 6
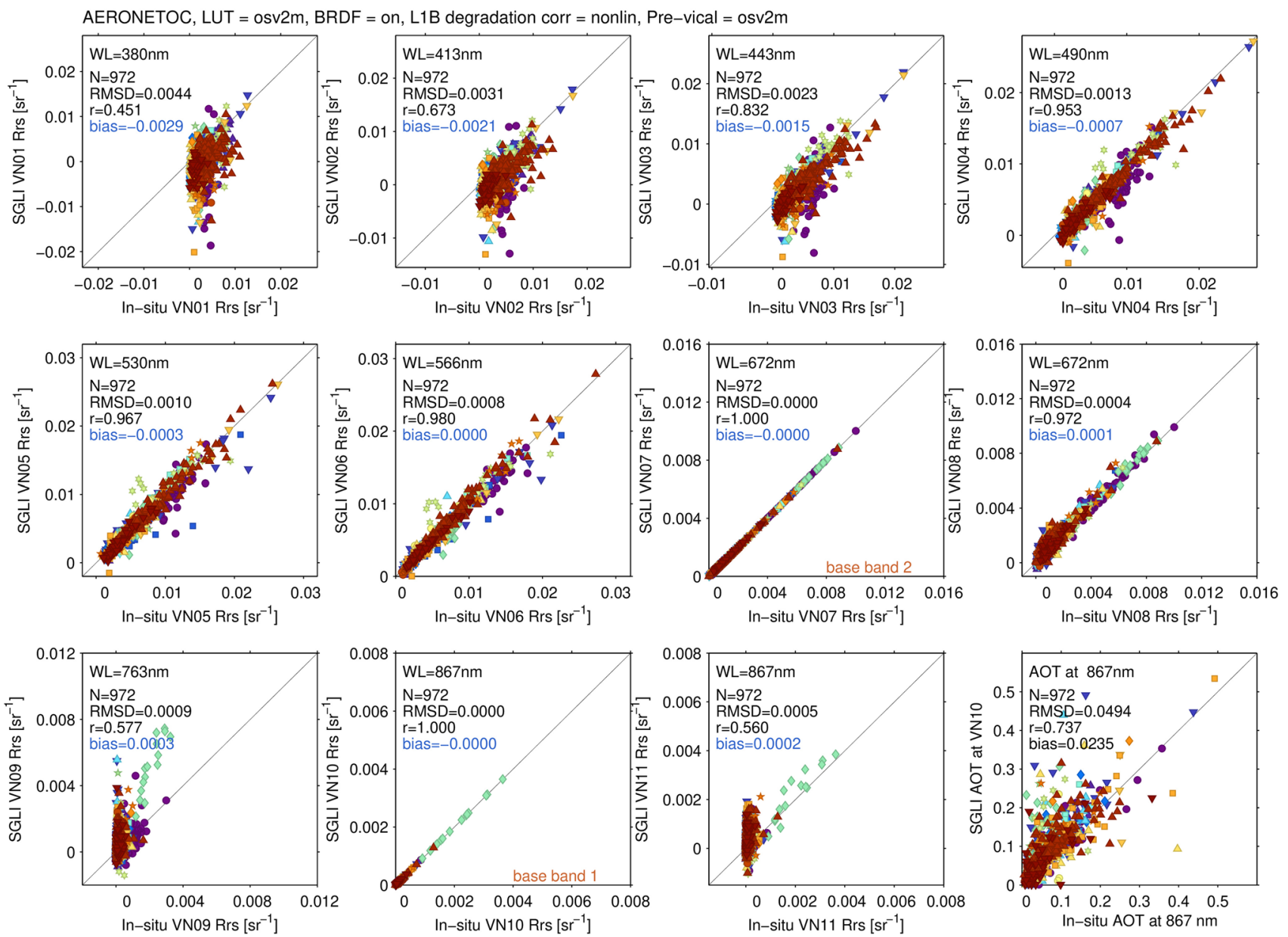

Fig. $6 R_{\mathrm{rs}}$ and AOT comparison between AERONET-OC measurements and estimates by LUT-A ( $\rho_{\mathrm{w}}$ in VN07 and VN10 are fixed to the AERONET-OC $R_{\mathrm{rs}}$ measurements at the wavelengths). $N$ indicates the match up sample number, RMSD shows root mean square
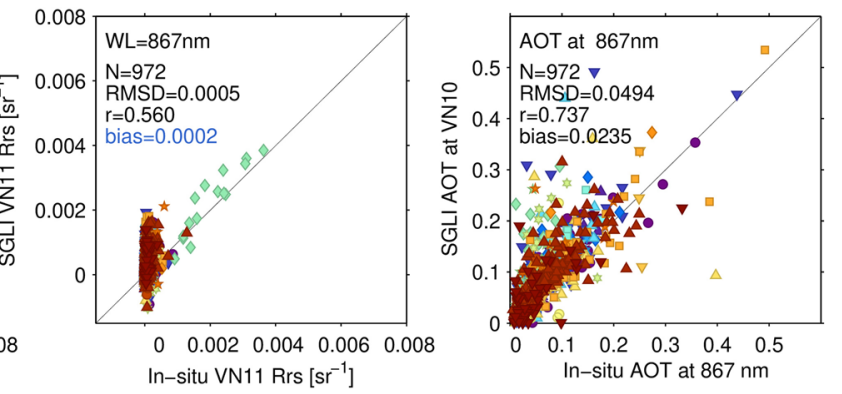

difference of SGLI estimates and in-situ data, $r$ is correlation coefficient, and bias denotes SGLI minus in-situ values. The units are steradian $^{-1}$ for $R_{\mathrm{rs}}$ and nondimensional for AOT. The marker colors correspond to the ones in Fig. 5 
at VN02-VN06 due to the $\pm 1 \%$ error of VN10 (and VN07) by using LUT-A are about $10 \%$ larger than the errors by using LUT-B (VN01 is influenced by errors from the spectral extrapolation of in-situ $R_{\mathrm{rs}}$ described in APPENDIX).

\section{4 $k_{v}$ in NIR and red by using in-situ aerosol measurements}

The $k_{v}$ in the red and NIR channels were estimated (not fixed to 1.0) when the AOT and $M_{\text {aerosol }}$ in the LUT were selected using AERONET-OC AOTs in the multiple channels (NIR and blue channels in this study). The $k_{v}$ becomes much larger than 1.0, especially at wavelengths longer than $530 \mathrm{~nm}$ (about 1.1 for LUT-A and 1.2 for LUT-B in VN10 in Fig. 8 and Table 2(d) and [d]).

\section{5 $k_{v}$ in NIR and red by using RadCalNet measurements}

The $k_{v}$ in the red and NIR channels were estimated (not fixed to 1.0) through the AOT and $M_{\text {aerosol }}$ in the LUT were selected using RadCalNet measurements of AOT and $\alpha$ (Fig. 8 and Table 2(e) and [e]). The $k_{v}$ from the RadCalNet sites are lower than $k_{v}$ from MOBY + BOUSSOLE by 4-5\% from NUV to green wavelengths; however, the difference is smaller in longer wavelengths, red and NIR channels. Note that this type of calibration differs from the system vicarious calibration performed at MOBY and BOUSSOLE, which uses the atmospheric correction scheme of the ocean color processing line. The 4-5\% differences in the blue and green would yield unacceptable $R_{\mathrm{rs}}$ errors, emphasizing that for ocean color remote sensing the MOBY + BOUSSOLE calibration cannot be substituted by a RadCalNet-type calibration.

\section{Discussion and conclusion}

\subsection{Calibration coefficients from different data sources and aerosol models}

The $k_{v}$ values obtained using different reference data are summarized in Table 2 and Fig. 8. Considering RMSD of $R_{\mathrm{rS}}$ compared with AERONET-OC, we recommend $k_{v}$ from MOBY + BOUSSOLE samples with LUT-A or LUT-B, i.e., $k_{v}$ of Table 2(c) or [c], as the SGLI ocean color vicarious calibration coefficients.

The difference of $k_{v}$ due to the LUTs (e.g., between Table 2(c) and [c]) is about $1 \%$. The difference on the $R_{\mathrm{rs}}$ estimates can be reduced if we use $k_{v}$ derived by the same LUT. On the other hand, the $1 \%$ difference can have significant impact on $R_{\mathrm{rs}}$ (as shown in Fig. 7) if we do not use the LUT which is selected to derive the $k_{v}$.
The difference between $k_{v}$ obtained with the MOBY dataset and the BOUSSOLE dataset is larger when using LUT-A than when using LUT-B (the difference for VN03 was 2.6\% and $1.6 \%$ by LUT-A and LUT-B, respectively). That seems to be due to the same reason as for the $R_{\mathrm{rs}}$ error discussed next (Sect. 5.2).

\subsection{Bias and deviation on $R_{\mathrm{rs}}$ and AOT by $k_{v}$ of different LUTs}

Comparison of errors of $R_{\mathrm{rs}}$ and AOT derived by the different LUT-A and -B for AERONET-OC is shown in Table 4. $R_{\mathrm{rs}}$ RMSD obtained using LUT-B is smaller in the NUVblue channels (VN01-VN04) by 12-16\% (see Table 4). That may be due to the higher spectral slope of $\rho_{\mathrm{a}}$ in LUT-A (the right panel of Fig. 2), causing larger deviation in $R_{\mathrm{rs}}$ at blue wavelengths from errors in NIR channels. The larger difference between $k_{v}$ from MOBY and BOUSSOLE in the case of LUT-A can be explained in the same way, i.e., by the error in representing the $\rho_{\mathrm{a}}$ of different aerosol types (the average $\alpha$ between 867 and $672 \mathrm{~nm}$ estimated by LUT-A was 0.79 and 1.25 for MOBY and BOUSSOLE, respectively) which is enhanced by the higher spectral slope of $\rho_{\mathrm{a}}$ in LUT-A.

On the other hand, LUT-A is recommended for the aerosol estimation regarding both RMSD and bias of AOT. The reason is that LUT-A includes smaller aerosol particle radius which has a higher ratio of backscattering reflectance per AOT, reducing the positive bias of AOT.

\section{$5.3 k_{v}$ in red and NIR}

We have used VN10 and VN07 to estimate the AOT and $M_{\text {aerosol }}$ in this analysis, which assumes that $k_{v}$ is 1.0 in the two channels. Departures from this assumption are possible, i.e., the $k_{v}$ of the two channels can be other than 1.0.

When we use AERONET-OC AOT at two wavelengths (i.e., VN10 and VN03 to cover blue to NIR wavelengths), $k_{v}$ becomes larger especially at wavelengths longer than $530 \mathrm{~nm}$ (more than 1.1 in VN10 as shown in Fig. 8 and Table 2(d) and $[\mathrm{d}])$. The $10 \%$ larger value than 1.0 (1.0 corresponds to the prelaunch gain) does not seem realistic considering the results of prelaunch and onboard calibration (Urabe et al. 2019) and RadCalNet $k_{v}$ (around 0.95-1.0 in Fig. 8) which were calculated using in-situ AOT and $\alpha$ measurements. This may indicate that the larger $k_{v} \mathrm{~s}$ for wavelengths longer than $530 \mathrm{~nm}$ are mainly caused by the small aerosol backscattering reflectance (i.e., $\rho_{\mathrm{a}}$ ) per a certain AOT in the LUTs, and the error becomes substantial over the ocean because the relative contribution of $\rho_{\mathrm{a}}$ to the $\rho_{\mathrm{t}}$ over the ocean (AERONET-OC) is larger than over land (RadCalNet) at those wavelengths.

The bias in $R_{\mathrm{rs}}$ can be reduced if we apply $k_{v}$ with the same LUT used to derive $k_{v}$ for both the processing by 


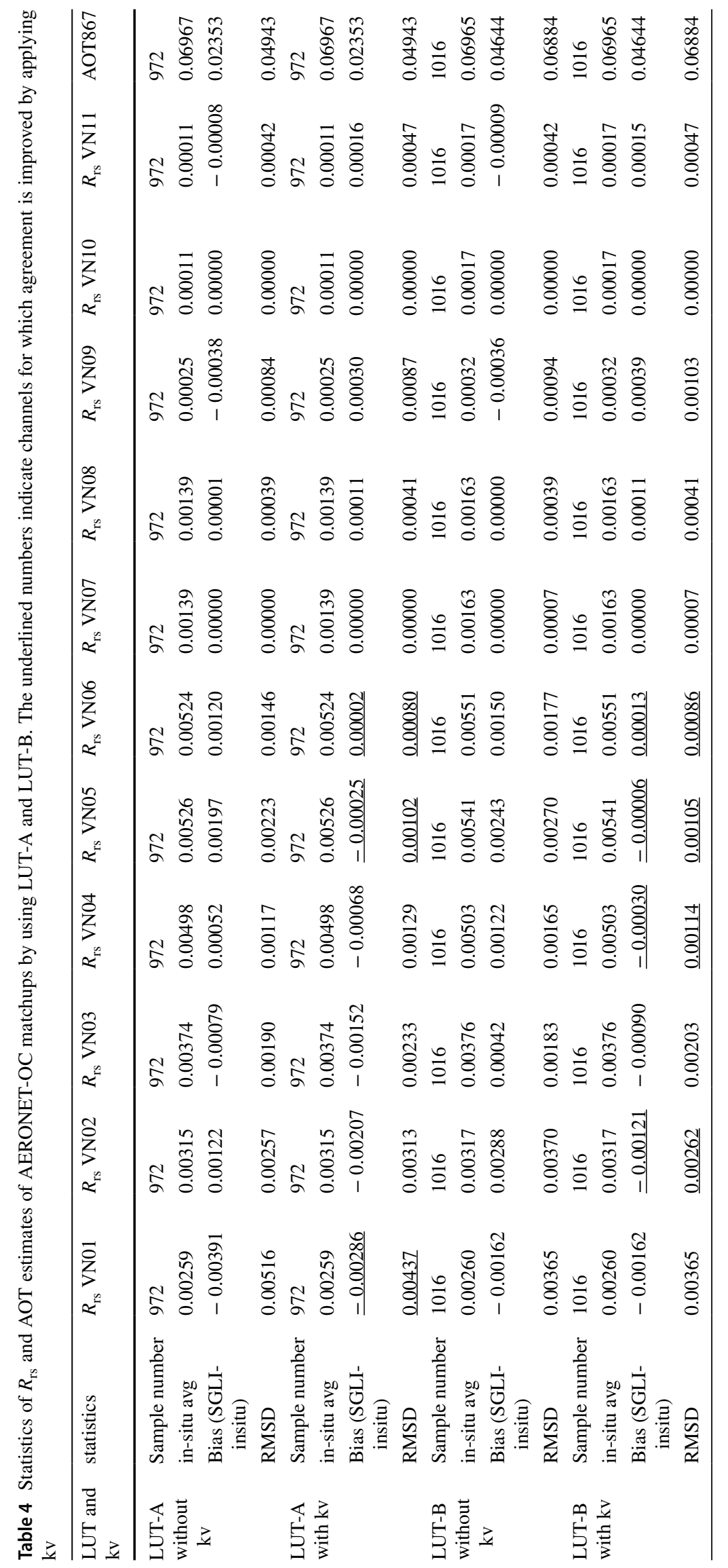


(A) LUT-A
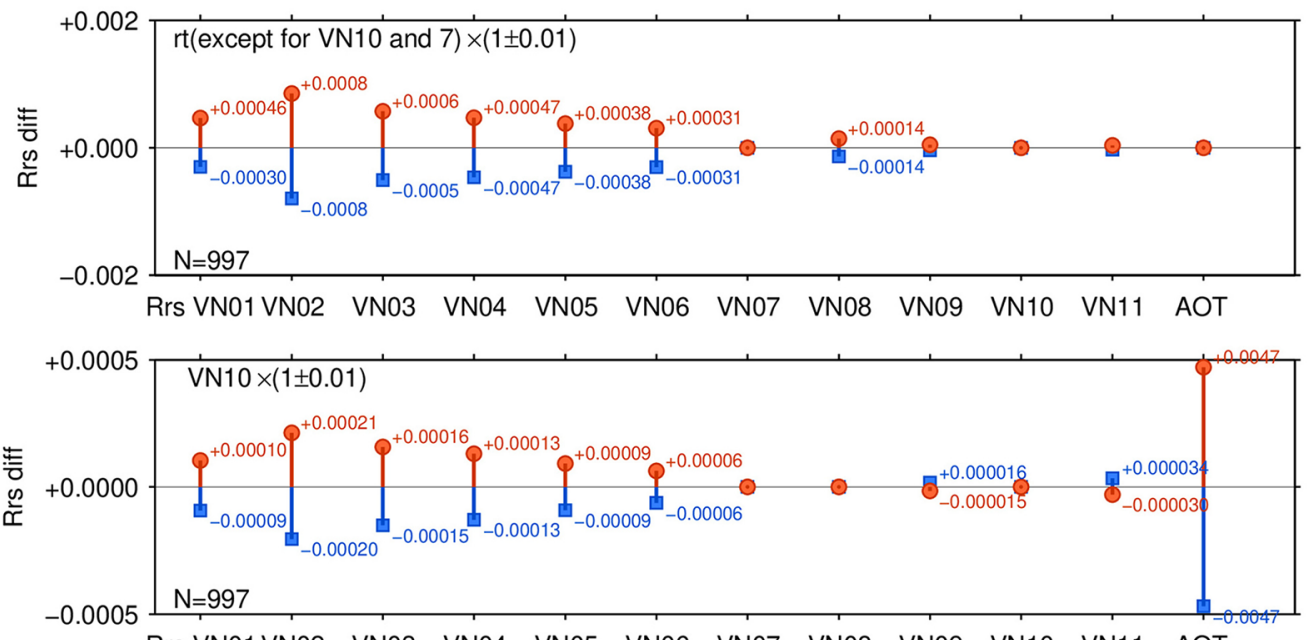

$\begin{array}{lllllllllll}\text { Rrs VN01 VN02 } & \text { VN03 } & \text { VN04 } & \text { VN05 } & \text { VN06 } & \text { VN07 } & \text { VN08 } & \text { VN09 } & \text { VN10 } & \text { VN11 } & \text { AOT }\end{array}$

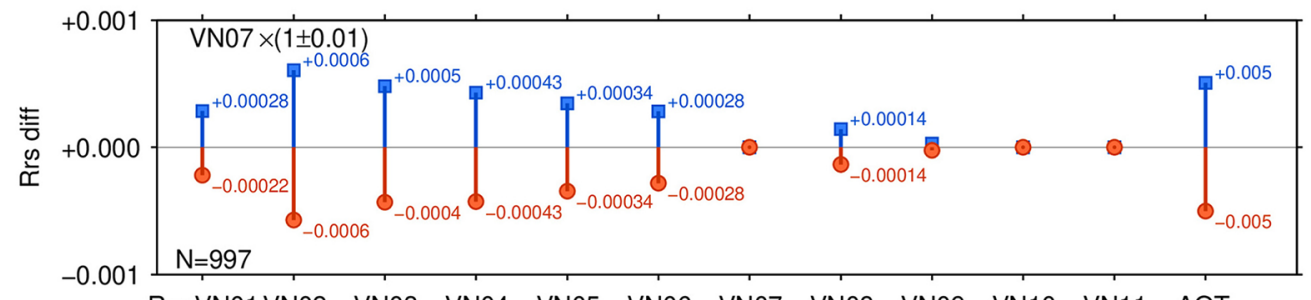

Rrs VN01 VN02 VN03 VN04 VN05 VN06 VN07 VN08 VN09 VN10 VN11 AOT

(B) LUT-B
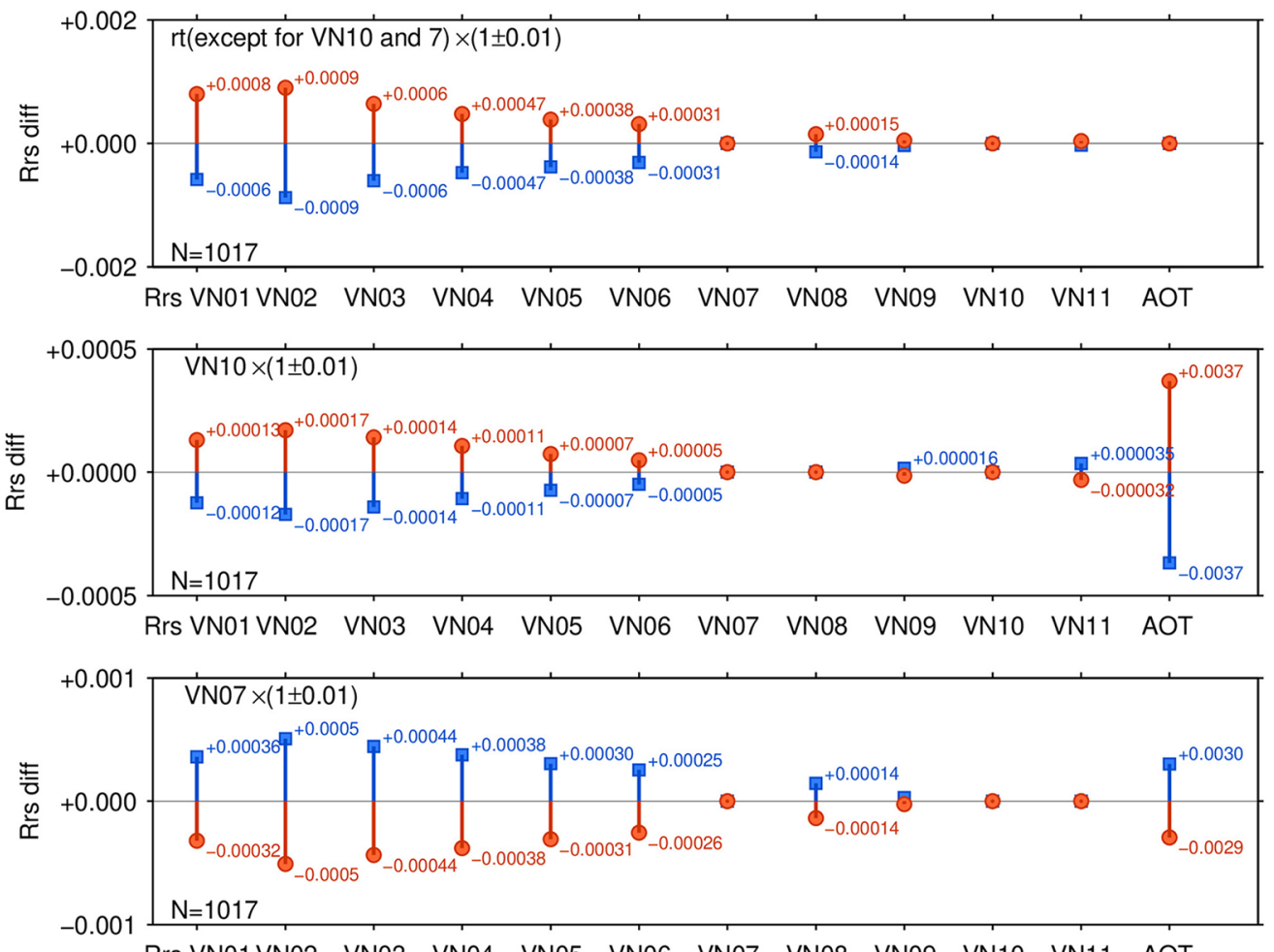

Fig. 7 Influence of the deviation of the vicarious calibration coefficients by A LUT-A and B LUT-B in the case of AERONET-OC matchups. The first, second, and third panels in $(\mathbf{A})$ and $(\mathbf{B})$ are $R_{\mathrm{rs}}$ errors resulting from $\rho_{\mathrm{t}}$ error in the same channels, $R_{\mathrm{rs}}$ and AOT errors resulting from $\rho_{\mathrm{t}}$ error in $\mathrm{VN} 10$, and $R_{\mathrm{rs}}$ and AOT errors resulting from $\rho_{\mathrm{t}}$ error in $\mathrm{VN} 07$, respectively 
LUT-A and LUT-B. However, this study indicates LUT-A is better for the AOT estimation and LUT-B is suitable for the $R_{\mathrm{rs}}$ estimation considering the validation results (RMSD in Table 4). It was decided, for version 3 of the SGLI standard AC algorithm has decided to use SVC coefficients (c) and LUT-A instead of -B to cover the wide range slope of the aerosol reflectance (Toratani et al. 2021). Further improvement of the aerosol LUT is needed to construct an optimal LUT for aerosol estimation that is consistent with other variables directly affected by absolute reflectance such as surface shortwave radiation and photosynthetically available radiation.

\section{Appendix}

\section{$R_{\mathrm{rs}}$ wavelength interpolation}

When the reference $R_{\mathrm{rs}}$ wavelengths are different from SGLI ones (cases of AERONET-OC), we interpolated (or extrapolated) using an inherent optical property (IOP) algorithm similarly as in Murakami et al. (2005).

We used a simple IOP model based on Gordon et al. (1988) and Lee et al. (2002) adjusted to IOP data in NASA bio-Optical Marine Algorithm Data set (NOMAD) (Werdell and Bailey 2005) and $R_{\mathrm{rs}}$ data, and interpolated NOMAD $R_{\mathrm{rs}}$ to $1 \mathrm{~nm}$ spectral resolution using the model. The IOP algorithms are based on the equation of remote sensing reflectance below the surface $\left(r_{\mathrm{rs}}\right)$, the total absorption coefficient ( $a$ ) and the backscattering coefficient $\left(b_{b}\right)$ proposed by Gordon et al. (1988).

Remote sensing reflectance above the surface, $R_{\mathrm{rs}}$ was estimated from $r_{\text {rs }}$ using the relation from Gordon et al. (1988) and Lee et al. (2002) as follows:

$$
\begin{aligned}
& R_{\mathrm{rs}}(\lambda)=0.529 \times r_{\mathrm{rs}}(\lambda) /\left(1-1.7 \times r_{\mathrm{rs}}(\lambda)\right), \\
& r_{\mathrm{rs}}(\lambda)=g_{1} \times u(\lambda)+g_{2} \times u(\lambda)^{2}, \\
& u(\lambda)=b_{\mathrm{b}}(\lambda) /\left(b_{\mathrm{b}}(\lambda)+a(\lambda)\right), \\
& a(\lambda)=a_{\mathrm{w}}(\lambda)+\left(a_{\mathrm{ph}}(\lambda)+a_{\mathrm{dg}}(\lambda)\right), \\
& b_{\mathrm{b}}(\lambda)=b_{\mathrm{bw}}(\lambda)+b_{\mathrm{bp}}(\lambda),
\end{aligned}
$$

where $r_{\mathrm{rs}}$ is the remote sensing reflectance below the surface at wavelength $\lambda, a$ is the total absorption coefficient, $a_{\mathrm{w}}$, the absorption spectra of water, $a_{\mathrm{ph}}$, the absorption spectra of phytoplankton, and $a_{\mathrm{dg}}$ the absorption spectra of detritus + colored dissolved organic matter, $b_{\mathrm{b}}$, the backscattering coefficient, and $b_{\mathrm{bw}}$ and $b_{\mathrm{bp}}$ are backscattering coefficients of water and particles respectively. We used $a_{\mathrm{w}}$ and $b_{\mathrm{bw}}$ values from Pope and Fry (1997), Kou et al. (1993), Lee et al. (2015) and $g_{1}=0.0949$ and $g_{2}=0.0794$ (Lee et al. 2002).

The spectral shape (normalized at $442 \mathrm{~nm}$ ) of phytoplankton absorption $a_{p h o}$ was modeled as the average from NOMAD data. The spectral shapes of $a_{\mathrm{dg}}$ and $b_{\mathrm{bp}}$ were approximated as follows:

$a_{\mathrm{dg} 0}(\lambda)=\exp (-S \times(\lambda-442))$,

$b_{\mathrm{bp} 0}(\lambda)=(\lambda / 442)^{-Y}$,

where $S$ and $Y$ are fixed at 0.0146 , and 1.18, respectively, values that were derived from the average of NOMAD in situ measurements of $a_{\mathrm{dg}}$ and $b_{\mathrm{bp}}$. The weighted values for the SGLI channels are listed in Table 5.

To simplify and improve the stability of the process, we assumed that the spectral shape of the $a_{\mathrm{pg}}=a_{\mathrm{ph}}+a_{\mathrm{dg}}$ can be represented as follows:

$a_{\mathrm{pg} 0}(\lambda)=\left(a_{\mathrm{ph} 0}(\lambda) \times r_{\mathrm{aph}}+a_{\mathrm{dg} 0}(\lambda)\right) /\left(r_{\mathrm{aph}}+1.0\right)$,

where $a_{\mathrm{ph} 0}$ is the phytoplankton absorption normalized to 1.0 at $442 \mathrm{~nm}$ derived from the average of NOMAD in situ measurements (Table 5), and $r_{\text {aph }}$ is set to 0.6 by the average of $a_{\mathrm{ph}} / a_{\mathrm{dg}}$ at $443 \mathrm{~nm}$ in NOMAD. The difference of $r_{\mathrm{aph}}$ can amplify uncertainty at $380 \mathrm{~nm}$ through the extrapolation; the bias and RMSD of $R_{\mathrm{rs}}$ at $380 \mathrm{~nm}$ are changed by -0.0005 and $+10 \%$, respectively, according to change of $r_{\text {aph }}$ from 0.33 to 0.67 . The $a_{\mathrm{pg}}$ and $b_{\mathrm{bp}}$ are described by $a_{\mathrm{pg}}$ and $b_{\mathrm{bp}}$ at $442 \mathrm{~nm}, a_{\mathrm{pg} 442}$ and $b_{\mathrm{bp} 442}$ as follows:

$a_{\mathrm{pg}}(\lambda)=a_{\mathrm{pg} 442} \times a_{\mathrm{pg} 0}(\lambda)$

$b_{\mathrm{bp}}(\lambda)=b_{\mathrm{bp} 442} \times b_{\mathrm{bp} 0}(\lambda)$

The $a_{\mathrm{pg} 442}$ and $b_{\mathrm{bp} 442}$ in Eqs. (A9) and (A10) were derived using two (blue and green) channels of the reference $R_{\mathrm{rs}}$ data by the linear matrix inversion (Hoge and Lyon 1996; 1999; Lyon and Hoge 2006) with Equations (A1-A8). The $R_{\mathrm{rs}}$ in channels of the reference dataset and channels of SGLI were calculated using $a_{\mathrm{pg} 442}$ and $b_{\mathrm{bp} 442}$ and Equations (A1-A10). The ratios between the reference $R_{\mathrm{rs}}$ and simulated $R_{\mathrm{rs}}$ were linearly interpolated to the SGLI channel wavelengths and applied to the simulated $R_{\mathrm{rs}}$ in the SGLI channels.

Acknowledgements We acknowledge all contributors to establishing, maintaining, and operationally supporting MOBY, BOUSSOLE, AERONET-OC, and RadCalNet, which are used as the calibration and validation references in this study. The MOBY operation and preprocessing for SGLI channels are funded by NOAA and the data was provided under MOU between NOAA and JAXA in relation to the Cooperation for Global Observing Satellite Missions. The BOUSSOLE data used in this work were collected when the project was funded by the European 
Fig. $8 k_{v}$ of SGLI derived by using $\mathbf{c}$ MOBY + BOUSSOLE, d MOBY + BOUSSOLE with AERONET-OC AOTs, and e RadCalNet surface reflectance by using LUT-A (solid lines) and LUT-B (dashed lines). The 95\% confidence level (assuming the $t$-distribution) is shown by the error bars. The horizontal positions are shifted to avoid the overlap of the plots

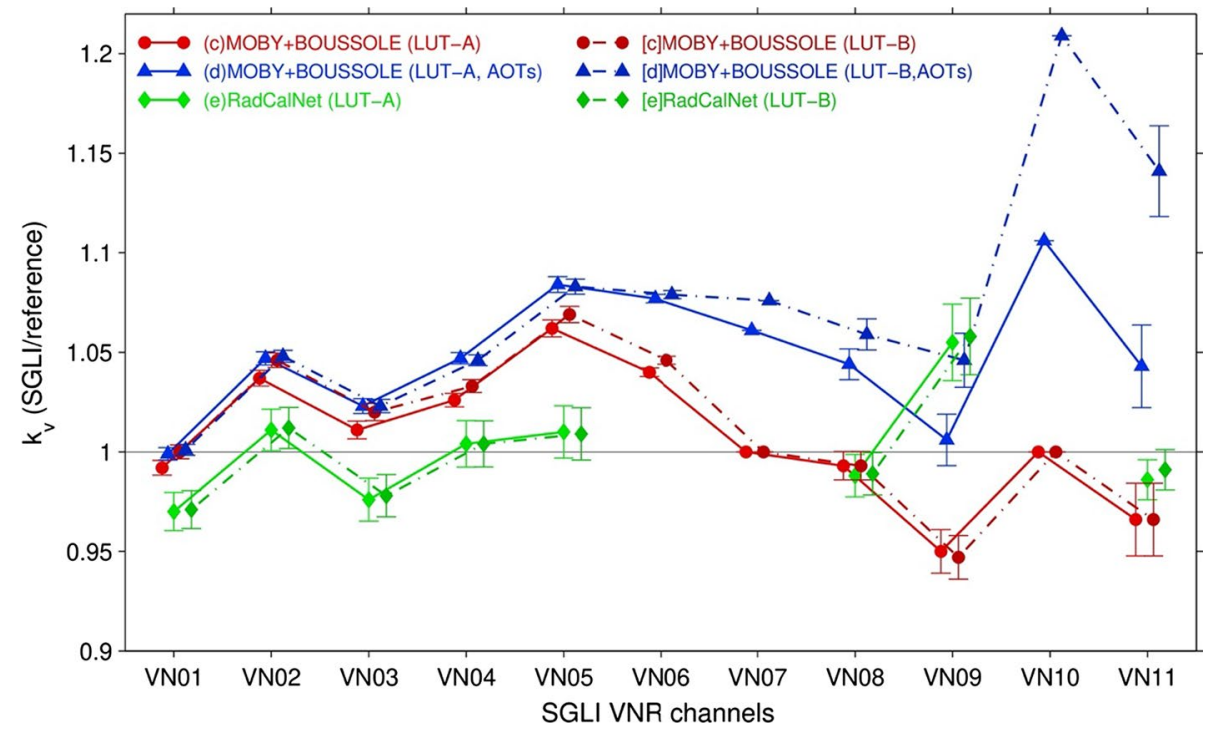

Table 5 Coefficients for the IOP model

\begin{tabular}{lcccccccccccccc}
\hline & VN01 & VN02 & VN03 & VN04 & VN05 & VN06 & VN07 & VN08 & VN09 & VN10 & VN11 \\
\hline$\lambda[\mathrm{nm}]$ & 380.0 & 412.5 & 443.2 & 489.9 & 529.6 & 566.2 & 672.0 & 672.1 & 763.1 & 866.8 & 867.1 \\
$a_{w}\left[\mathrm{~m}^{-1}\right]$ & 0.00377 & 0.00312 & 0.00510 & 0.01337 & 0.04211 & 0.06759 & 0.44573 & 0.44603 & 2.85710 & 4.69239 & 4.70505 \\
$b_{b w}\left[\mathrm{~m}^{-1}\right]$ & 0.00472 & 0.00333 & 0.00239 & 0.00157 & 0.00112 & 0.00086 & 0.00041 & 0.00041 & 0.00024 & 0.00014 & 0.00014 \\
$a_{p h 0}\left[\mathrm{~m}^{-1}\right]$ & 0.65516 & 0.84190 & 0.98772 & 0.61764 & 0.30408 & 0.14737 & 0.58058 & 0.58094 & 0.00000 & 0.00000 & 0.00000 \\
$a_{d g 0}\left[\mathrm{~m}^{-1}\right]$ & 2.48076 & 1.54306 & 0.98477 & 0.49841 & 0.27957 & 0.16400 & 0.03501 & 0.03496 & 0.00922 & 0.00204 & 0.00203 \\
$b_{b p 0}\left[\mathrm{~m}^{-1}\right]$ & 1.19554 & 1.08524 & 0.99705 & 0.88615 & 0.80830 & 0.74718 & 0.61056 & 0.61045 & 0.52557 & 0.45232 & 0.45210 \\
\hline
\end{tabular}

Space Agency (ESA, contract 4000119096/17/I-BG), the Centre National d'Etudes Spatiales (CNES), and the Japan Aerospace Exploration Agency (JAXA, contracts ER2GCF308: JX-PSPC-530175).

Open Access This article is licensed under a Creative Commons Attribution 4.0 International License, which permits use, sharing, adaptation, distribution and reproduction in any medium or format, as long as you give appropriate credit to the original author(s) and the source, provide a link to the Creative Commons licence, and indicate if changes were made. The images or other third party material in this article are included in the article's Creative Commons licence, unless indicated otherwise in a credit line to the material. If material is not included in the article's Creative Commons licence and your intended use is not permitted by statutory regulation or exceeds the permitted use, you will need to obtain permission directly from the copyright holder. To view a copy of this licence, visit http://creativecommons.org/licenses/by/4.0/.

\section{References}

Antoine D, Morel A (1999) A multiple scattering algorithm for atmospheric correction of remotely sensed ocean color (MERIS instrument): principle and implementation for atmospheres carrying various aerosols including absorbing ones. Int J Remote Sens 20(9):1875-1916. https://doi.org/10.1080/014311699212533
Antoine D, Chami M, Claustre H, D’Ortenzio F, Morel A, Bécu G, Gentili B, Louis F, Ras J, Roussier E, Scott AJ, Tailliez D, Hooker SB, Guevel P, Desté JF, Dempsey C, Adams D (2006) BOUSSOLE : a joint CNRS-INSU, ESA, CNES and NASA Ocean Color Calibration And Validation Activity. NASA Technical memorandum 2006-214147, NASA/GSFC, Greenbelt, MD, pp 61

Antoine D, D'Ortenzio F, Hooker SB, Bécu G, Gentili B, Tailliez D, Scott A (2008a) Assessment of uncertainty in the ocean reflectance determined by three satellite ocean color sensors (MERIS, SeaWiFS, MODIS) at an offshore site in the Mediterranean Sea (BOUSSOLE project). J Geophys Res 113:C07013. https://doi. org/10.1029/2007JC004472

Antoine D, Guevel P, Desté JF, Bécu G, Louis F, Scott AJ, Bardey P (2008b) The «BOUSSOLE » buoy-a new transparent-to-swell taut mooring dedicated to marine optics : design, tests and performance at sea. J Atmos Oceanic Tech 25:968-989. https://doi. org/10.1175/2007JTECHO563.1

Bouvet M, Thome K, Berthelot B, Bialek A, Czapla-Myers J, Fox NP, Goryl P, Henry P, Ma L, Marcq S, Meygret A, Wenny BN, Woolliams ER (2019) RadCalNet: a radiometric calibration network for earth observing imagers operating in the visible to shortwave infrared spectral range. Remote Sens 11:2401. https://doi.org/10. 3390/rs11202401

Clark DK, Gordon HR, Voss KJ, Ge Y, Brokenow W, Trees C (1997) Validation of atmospheric correction over oceans. J Geophys Res 102(D14):17209-17217. https://doi.org/10.1029/96JD03345 
Clark D, Yarbrough M, Feinholz M, Flora S, Broenkow W, Kim Y, Johnson B, Brown S, Yuen M, Mueller J (2003) MOBY, a radiometric buoy for performance monitoring and vicarious calibration of satellite ocean color sensors: Measurement and data analysis protocols. Ocean optics protocols for satellite ocean color sensor validation Rev. 4, Vol. VI, NASA Tech. memorandum 2003211621, NASA GSFC, Greenbelt, MD, pp 141

Cox C, Munk W (1954) Measurement of the roughness of the sea surface from photographs of the sun's glitter. J Opt Soc Amer 44(11):838-850. https://doi.org/10.1364/JOSA.44.000838

Deushi M, Shibata K (2011) Development of a Meteorological Research Institute chemistry-climate model version 2 for the study of tropospheric and stratospheric chemistry. Pap Meteorol Geophys 62:1-46. https://doi.org/10.2467/mripapers.62.1

Eplee RE, Robinson WD, Bailey SW, Clark DK, Werdell PJ, Wang M, Barnes RA, McClain CR (2001) Calibration of SeaWiFS. II. Vicarious techniques. Appl Opt 40(36):6701-6718. https://doi. org/10.1364/AO.40.006701

Franz BA, Bailey SW, Werdell PJ, McClain CR (2007) Sensor-independent approach to the vicarious calibration of satellite ocean colour radiometry. Appl Opt 46(22):5068-5082. https://doi.org/ 10.1364/AO.46.005068

Gordon HR (1998) In-orbit calibration strategy for ocean color sensors. Remote Sens Environ 63(3):265-278. https://doi.org/10. 1016/S0034-4257(97)00163-6

Gordon HR, Wang M (1994) Retrieval of water-leaving radiance and aerosol optical thickness over the oceans with SeaWiFS: a preliminary algorithm. Appl Opt 33(3):443-452. https://doi.org/10. 1364/AO.33.000443

Gordon HR, Brown OB, Evans RH, Brown JW, Smith RC, Baker KS, Clark DK (1988) A semi-analytic radiance model of ocean color. J Geophys Res 93(D9):10909-10924. https://doi.org/10.1029/ JD093iD09p10909

Hoge FE, Lyon PE (1996) Satellite retrieval of inherent optical properties by linear matrix inversion of oceanic radiance models: an analysis of model and radiance measurement errors. J Geophys Res 101(C7):16631-16648. https://doi.org/10.1029/96JC01414

Hoge FE, Lyon PE (1999) Spectral parameters of inherent optical property models: methods for satellite retrieval by matrix inversion of an oceanic radiance model. Appl Opt 38(9):1657-1662. https:// doi.org/10.1364/AO.38.001657

Kou L, Labrie D, Chylek P (1993) Refractive indices of water and ice in the 0.65-2.5 $\mu \mathrm{m}$ spectral range. Appl Opt 32(19):3531-3540. https://doi.org/10.1364/AO.32.003531

Lee ZP, Carder KL, Arnone RA (2002) Deriving inherent optical properties from water color: a multiband quasi-analytical algorithm for optically deep waters. Appl Opt 41(27):5755-5772. https://doi. org/10.1364/AO.41.005755

Lee ZP, Wei J, Voss K, Lewis M, Bricaud A, Huot Y (2015) Hyperspectral absorption coefficient of "pure" seawater in the range of $350-550 \mathrm{~nm}$ inverted from remote sensing reflectance. Appl Opt 54(3):546-558. https://doi.org/10.1364/AO.54.000546

Lyon P, Hoge F (2006) The Linear Matrix Inversion Algorithm. In: Lee Z-P ed. Chap. 7 of IOCCG Report Number 5, Remote Sensing of Inherent Optical Properties: Fundamentals, Tests of Algorithms, and Applications. International Ocean-Colour Coordinating Group (IOCCG), Dartmouth, NS, Canada, pp 49-56. https://doi. org/10.25607/OBP-96

Morel A, Gentili B (2009) The dissolved yellow substance and the shades of blue in the Mediterranean Sea. Biogeosciences 6(11):2625-2636. https://doi.org/10.5194/bg-6-2625-2009

Morel A, Antoine D, Gentili B (2002) Bidirectional reflectance of oceanic waters: accounting for Raman emission and varying particle phase function. App Opt 41(30):6289-6306. https://doi.org/10. 1364/AO.41.006289
Morel A, Claustre H, Antoine D, Gentili B (2007) Natural variability of bio-optical properties in Case 1 waters: attenuation and reflectance within the visible and near-UV spectral domains, as observed in South Pacific and Mediterranean waters. Biogeosciences 4(5):913-925. https://doi.org/10.5194/bg-4-913-2007

Murakami H (2020) ATBD of GCOM-C/SGLI Land Atmospheric Correction Algorithm. JAXA EORC GCOM-C webpage https:// suzaku.eorc.jaxa.jp/GCOM_C/data/ATBD/ver2/V2ATBD_T1A_ BRDF_Murakami.pdf. Accessed 12 Dec 2021

Murakami H, Yoshida M, Tanaka K, Fukushima H, Toratani M, Tanaka A, Senga Y (2005) Vicarious calibration of ADEOS-2 GLI visible to shortwave infrared bands using global datasets. IEEE Trans Geosci Remote Sens 43(7):1571-1584. https://doi.org/10.1109/ TGRS.2005.848425

Nakajima T, Tanaka M (1986) Matrix formulation for the transfer of solar radiation in a plane-parallel scattering atmosphere. J Quant Spectrosc Radiat Transfer 35(1):13-21. https://doi.org/10.1016/ 0022-4073(86)90088-9

Nakajima T, Tanaka M (1988) Algorithms for radiative intensity calculations in moderately thick atmospheres using a truncation approximation. J Quant Spectrosc Radiat Transfer 40(1):51-69. https://doi.org/10.1016/0022-4073(88)90031-3

Okamura Y, Hashiguch T, Urabe T, Tanaka K, Yoshida J, Sakashita T, Amano T (2018) Pre-launch characterization and in-orbit calibration of GCOM-C/SGLI. IEEE Int Geosci Remote Sens Symp 2018:6651-6654. https://doi.org/10.1109/IGARSS.2018.8519151

Omar AH, Won JG, Winker DM, Yoon SC, Dubovik O, McCormick MP (2005) Development of global aerosol models using cluster analysis of Aerosol Robotic Network (AERONET) measurements. J Geophys Res 110:D10S14. https://doi.org/10.1029/2004JD0048 74

Ota Y, Higurashi A, Nakajima T, Yokota T (2010) Matrix formulations of radiative transfer including the polarization effect in a coupled atmosphere-ocean system. J Quant Spectrosc Radiat Transfer 111:878-894. https://doi.org/10.1016/j.jqsrt.2009.11.021

Pope RM, Fry ES (1997) Absorption spectrum (380-700 nm) of pure water. II. Integrating cavity measurements. Appl Opt 36(33):8710-8723. https://doi.org/10.1364/AO.36.008710

Sayer AM, Smirnov A, Hsu NC, Holben BN (2012) A pure marine aerosol model, for use in remote sensing applications. J Geophys Res 117:D05213. https://doi.org/10.1029/2011JD016689

Shettle EP, Fenn RW (1979) Models for the Aerosols of the Lower Atmosphere and the Effects of Humidity Variations on Their Optical Properties. Report No. AFGL-TR-79-0214, U.S. Air Force Geophysics Laboratory, Hanscom Air Force Base, Mass, pp 94

Shibata K, Deushi M, Sekiyama TT, Yoshimura H (2005) Development of MRI chemical transport model for the study of stratospheric chemistry. Pap Meteorol Geophys 55:75-119. https://doi.org/10. 2467/mripapers.55.75

Siegel DA, Wang M, Maritorena S, Robinson W (2000) Atmospheric correction of satellite ocean color imagery: the black pixel assumption. Appl Opt 39(21):3582-3591. https://doi.org/10.1364/ AO.39.003582

Stamnes K, Tsay SC, Wiscombe W, Jayaweera K (1988) Numerically stable algorithm for discrete-ordinate-method radiative transfer in multiple scattering and emitting layered media. Appl Opt 27(12):2502-2509. https://doi.org/10.1364/AO.27.002502

Tanaka K, Okamura Y, Mokuno M, Amano T, Yoshida J (2018) First year on-orbit calibration activities of SGLI on GCOM-C satellite. In: Proc. SPIE 10781, Earth Observing Missions and Sensors: Development, Implementation, and Characterization V, 107810Q (23 October 2018). https://doi.org/10.1117/12.2324703

Thuillier G, Hersé M, Simon PC, Labs D, Mandel H, Gillotay D, Foujols T (2003) The solar spectral irradiance from 200 to $2400 \mathrm{~nm}$ as measured by the SOLSPEC spectrometer from the ATLAS 1-2-3 
and EURECA missions. Sol Phys 214(1):1-22. https://doi.org/10. 1023/A:1024048429145

Toratani M, Fukushima H, Murakami H, Tanaka A (2007) Atmospheric correction scheme for GLI with absorptive aerosol correction. J Oceanogr 63:525-532. https://doi.org/10.1007/ s10872-007-0047-0

Toratani M, Ogata K, Fukushima H (2020) Atmospheric correction algorithm for ocean color Version 2 July 3 2020, SGLI Algorithm Theoretical Basis Document. JAXA EORC GCOM-C homepage https://suzaku.eorc.jaxa.jp/GCOM_C/data/ATBD/ver2/V2ATBD_ O2AB_NWLR_Toratani_r3.pdf. Accessed 12 Dec 2021

Toratani M, Ogata K, Fukushima H (2021) Atmospheric correction algorithm for ocean color Version 3 Oct. 28 2021, SGLI Algorithm Theoretical Basis Document. JAXA EORC GCOM-C homepage https://suzaku.eorc.jaxa.jp/GCOM_C/data/ATBD/ver3/ V3ATBD_O2AB_NWLR_toratani.pdf. Accessed 12 Dec 2021

Uchikata T, Tanaka K, Okamura,Y, Tsuida S, Amano T (2014) Proto Flight Model (PFM) performance and development status of Visible and Near Infrared Radiometer (VNR) on the Second-generation Global Imager (SGLI). In: Proceedings of SPIE, 9264, 92640Q (November 26, 2014). https://doi.org/10.1117/12.20685 58

Urabe T, Xiong X, Hashiguchi T, Ando S, Okamura Y, Tanaka K, Mokuno M (2019) Lunar Calibration Inter-Comparison of SGLI, MODIS and VIIRS. In: Proc. of IEEE/IGARSS, pp. 8481-8484 (28 July 2019). https://doi.org/10.1109/IGARSS.2019.8897892

Urabe T, Xiong X, Hashiguchi T, Ando S, Okamura Y, Tanaka K (2020) Radiometric model and inter-comparison results of the SGLI-VNR on-board calibration. Remote Sens 12(1):69. https:// doi.org/10.3390/rs12010069

Wang M, Gordon HR (1994) A simple, moderately accurate, atmospheric correction algorithm for SeaWiFS. Remote Sens Environ 50(3):231-239. https://doi.org/10.1016/0034-4257(94)90073-6

Werdell PJ, Bailey SW (2005) An improved bio-optical data set for ocean color algorithm development and satellite data product validation. Remote Sens Environ 98:122-140. https://doi.org/10. 1016/j.rse.2005.07.001

Yoshida M (2020) ATBD of GCOM-C aerosol properties algorithm. JAXA EORC GCOM-C homepage https://suzaku.eorc.jaxa.jp/ GCOM_C/data/ATBD/ver2/V2ATBD_A3AB_ARNP_Yoshida. pdf. Accessed 12 Dec 2021
Yoshida M, Murakami H, Mitomi Y, Hori M, Thome KJ, Clark DK, Fukushima H (2005) Vicarious calibration of GLI by ground observation data. IEEE Trans Geosci Remote Sens 43(10):21672176. https://doi.org/10.1109/TGRS.2005.856113

Yoshida M, Kikuchi M, Nagao TM, Murakami H, Nomaki T, Higurashi A (2018) Common retrieval of atmospheric aerosol properties for imaging satellite sensors. J Meteorol Soc Japan 96B:193-209. https://doi.org/10.2151/jmsj.2018-039

Yoshida M, Yumimoto K, Nagao TM, Tanaka TY, Kikuchi M, Murakami H (2021) Satellite retrieval of aerosol combined with assimilated forecast. Atmos Chem Phys 21:1797-1813. https:// doi.org/10.5194/acp-21-1797-2021

Zibordi G, Mélin F (2017) An evaluation of marine regions relevant for ocean colour system vicarious calibration. Remote Sens Environ 190:122-136. https://doi.org/10.1016/j.rse.2016.11.020

Zibordi G, Holben B, Hooker SB, Melin F, Berthon JF, Slutsker I, Giles D, Vandemark D, Feng H, Rutledge K, Schuster G, Mandoos AA (2006) A network for standardized ocean color validation measurements. Eos Trans Amer Geophys Union 87(30):293-297. https://doi.org/10.1029/2006EO300001

Zibordi G, Mélin F, Berthon JF, Holben B, Slutsker I, Giles D, D'Alimonte D, Vandemark D, Feng H, Schuster G, Fabbri BE, Kaitala S, Seppälä J (2009) AERONET-OC: a network for the validation of ocean color primary products. J Atmos Oceanic Technol 26:1634-1651. https://doi.org/10.1175/2009JTECHO654.1

Zibordi G, Mélin F, Voss KJ, Johnson BC, Franz BA, Kwiatkowska E, Huot JP, Wang M, Antoine D (2015) System vicarious calibration for ocean colour climate change applications: requirements for in situ data. Remote Sens Environ 159:361-369. https://doi.org/ 10.1016/j.rse.2014.12.015

Zibordi G, Bailey S, Antoine D, Goryl P, Kwiatkowska E, Wang M, Franz B, Johnson C, Murakami H, Park YJ, Chauhan P, Fougnie B (2016) International Network for Sensor Inter-comparison and Uncertainty assessment for Ocean Color Radiometry (INSITUOCR). INSITU-OCR White Paper, https://ioccg.org/what-we-do/ ceos-ocr-vc/. Accessed 12 Dec 2021

Zibordi G, Holben BN, Talone M, D'Alimonte D, Slutsker I, Giles DM, Sorokin MG (2021) Advances in the ocean color component of the aerosol robotic network (AERONET-OC). J Atmos Oceanic Tech 38(4):725-746. https://doi.org/10.1175/JTECH-D-20-0085.1 